\title{
Unfavorable Vascular Anatomy during Endovascular Treatment of Stroke: Challenges and Bailout Strategies
}

\author{
Francisco José Arruda Mont Alverne, ${ }^{\mathrm{a}}$ Fabricio Oliveira Lima, ${ }^{\mathrm{b}}$ Felipe de Araújo Rocha, ${ }^{\mathrm{a}, \mathrm{b}}$ \\ Diego de Almeida Bandeira, ${ }^{\mathrm{a}, \mathrm{b}}$ Adson Freitas de Lucena, ${ }^{\mathrm{a}, \mathrm{b}}$ Henrique Coelho Silva, ${ }^{\mathrm{a}, \mathrm{b}}$ \\ Jin Soo Lee, ${ }^{\mathrm{c}}$ Raul Gomes Nogueira ${ }^{\mathrm{d}}$
}

anterventional Neuroradiology Service, Hospital Geral de Fortaleza, Fortaleza, Brazil

${ }^{b}$ Neurology Service, Hospital Geral de Fortaleza, Fortaleza, Brazil

'Department of Neurology, Ajou University Hospital, Ajou University School of Medicine, Suwon, Korea

${ }^{d}$ Department of Neurology, Marcus Stroke \& Neuroscience Center, Grady Memorial Hospital, Emory University School of Medicine, Atlanta, GA, USA

The benefit of mechanical thrombectomy (MT) in acute ischemic stroke (AIS) due to large vessel intracranial occlusions is directly related to the technical success of the procedures in achieving fast and complete reperfusion. While a precise definition of refractoriness is lacking in the literature, it may be considered when there is reperfusion failure, long procedural times, or high number of passes with the MT devices. Detailed knowledge about the causes for refractory MT in AIS is limited; however, it is most likely a multifaceted problem including factors related to the vascular anatomy and the underlying nature of the occlusive lesion amongst other factors. We aim to review the impact of several key unfavorable anatomical factors that may be encountered during endovascular AIS treatment and discuss potential bail-out strategies to these challenging situations.

Keywords Stroke; Brain ischemia; Reperfusion; Thrombectomy

\author{
Correspondence: Raul Gomes \\ Nogueira \\ Department of Neurology, Marcus \\ Stroke \& Neuroscience Center, Grady \\ Memorial Hospital, Emory University \\ School of Medicine, 49 Jesse Hill \\ Drive SE Room\# 333, Atlanta, GA \\ 30303, USA \\ Tel: +1-404-616-4013 \\ Fax: +1-404-659-0849 \\ E-mail: raul.g.nogueira@emory.edu \\ Received: January 22, 2020 \\ Revised: May 5, 2020 \\ Accepted: May 6, 2020
}

\section{Introduction}

Major technical improvements in mechanical thrombectomy (MT) have resulted in significantly higher rates of revascularization and improved clinical outcomes in acute ischemic stroke (AIS) due to large vessel intracranial occlusion (LVO). Nine landmark randomized controlled trials (RCTs) have established the clinical efficacy of mechanical reperfusion compared to medical treatment alone in both early and late time windows. ${ }^{1-9}$ However, morbidity and mortality remain considerable in LVO patients despite MT, as demonstrated by the high rates of long-term functional dependency (90-day modified Rankin
Scale [mRS] score 3-6: $28 \%$ to $67.4 \%$ ) and mortality (9\% to $24 \%$ ) across these studies. ${ }^{1-9}$

The benefit of MT in AIS is directly related to the technical success of the procedures in achieving fast and complete reperfusion. Despite advances in endovascular treatment for AIS, the rates of favorable reperfusion (modified treatment in cerebral infarction $[\mathrm{mTICl}] \geq 2 \mathrm{~b}$ ) have ranged from $68 \%$ to $88 \%$ in recent trials. ${ }^{1-9}$ Achieving favorable reperfusion often requires multiple thrombectomy attempts and the use of rescue devices and drugs. Full reperfusion is infrequently accomplished during the first device pass. ${ }^{10}$ In addition to prolonging procedure time, multiple device passes may promote arterial endothelial 
injury, potentially reducing clinical efficacy while increasing the occurrence of adverse events. ${ }^{11-14}$

The Highly Effective Reperfusion Using Multiple Endovascular Devices (HERMES) trials pooled analysis of the first five contemporary MT trials reported that the probability of functional independence (mRS 0-2) at 3 months declined from $64.1 \%$ with a symptom onset-to-reperfusion time of $180 \mathrm{~min}$ utes to $46.1 \%$ with a symptom onset-to-reperfusion time of 480 minutes. ${ }^{15}$ The procedural time (PT) might represent a significant proportion of the onset-to-reperfusion time in technically challenging scenarios. ${ }^{16}$ Many studies have reported that the longer the PT, the higher the risk of hemorrhagic transformation and the lower the odds of good clinical outcome. . $^{13,17-21}$

While a precise definition of refractory thrombectomy (RT) is lacking, it may be defined as a procedure that lasts too long, requires greater than three passes, or is not successful in obtaining an acceptable degree of reperfusion ( $\mathrm{TICl} \geq 2 \mathrm{~b}$ ). $\mathrm{RT}$ is a multifaceted problem comprising factors related to the patient (vascular anatomy and the underlying nature of the occlusive lesion including thrombus composition and the presence of atherosclerotic plaque) and the procedure (proper device and technique selection). ${ }^{11,13,14,22-24}$

Herein, we aim to review the impact of some of the key unfavorable anatomical factors that may be encountered during endovascular AIS treatment and discuss potential bail-out strategies to these challenging situations.

\section{Unfavorable supra-aortic access}

Unfavorable vascular anatomy is a common challenge to neurointerventional procedures. This anatomy may be encountered either in isolation or in combination at many different levels including the aortic arch, common carotid artery
(CCA), cervical internal carotid artery (ICA), carotid siphon, and intracranial circulation. Difficult transfemoral catheter access to the target artery is related to a longer PT, lower rate of recanalization, and lower rate of favorable outcome. Kaesmacher et al. ${ }^{23}$ reported that failure to reach the target occlusion, one of the reasons for reperfusion failure, might occur in up to one of three patients (20 of 63 patients; $31.7 \%$; $95 \%$ confidence interval, $20.3 \%$ to $43.2 \%$ ). The inability to reach the occluded vessel was generally related to complex arterial anatomy at the level of the aortic arch or cervical vessel tortuosity. ${ }^{23}$

Complex aortic arch and carotid artery anatomy are associated with atherosclerotic burden and are more often present in elderly patients. ${ }^{25}$ Ribo et al. ${ }^{14}$ reported a median time from groin puncture to carotid catheterization of 20 minutes. They proposed a risk score to identify high-risk patients for challenging supra-aortic access (groin puncture to carotid catheterization $>30$ minutes) that included hypertension, age $>75$ years, dyslipidemia, and left anterior circulation stroke. A score $>2$ predicted difficult access, with a sensitivity of $84 \%$ and a specificity of $74 \% .^{14}$

Snelling et al. ${ }^{20}$ proposed a score based on anatomic criteria including the type of aortic arch as well as the presence of bovine arch and ICA dolicoarteriopathy. Higher scores were independently predictive of longer time from groin puncture to first pass, lower reperfusion (TICl) scores, and unfavorable clinical outcomes after thrombectomy. ${ }^{20}$ Pre-operative analysis of computed tomography angiography may rapidly and consistently identify vascular features that may be related to difficult access to supra-aortic vessels (Table 1) and aid in planning appropriate operative strategies (Figures 1 and 2, types of aortic arch).

Table 1. Features related to challenging supra-aortic access

\begin{tabular}{|c|c|c|}
\hline Unfavorable vascular features & Initial operative strategy & Observation \\
\hline Leriche syndrome & $\begin{array}{l}\text { Direct carotid puncture } \\
\text { Transradial access }\end{array}$ & $\begin{array}{l}\text { Initial option for anterior circulation stroke } \\
\text { Initial option for posterior circulation stroke }\end{array}$ \\
\hline Aortic arch morphology type II & Coaxial technique with Vitek diagnostic catheter & Usually no further strategy is necessary. \\
\hline Aortic arch morphology type III & Coaxial technique with Vitek diagnostic catheter & $\begin{array}{l}\text { Alternatives strategies are the use of multiple guidewires and } \\
\text { balloon-anchoring technique. }\end{array}$ \\
\hline Bovine aortic arch variant & Coaxial technique with Vitek diagnostic catheter & $\begin{array}{l}\text { In case of failure with the use of multiple guidewires and bal- } \\
\text { loon-anchoring technique, we favor transradial approach. }\end{array}$ \\
\hline $\begin{array}{l}\text { Acute angle turn of common carotid } \\
\text { artery }\end{array}$ & Coaxial technique with Vitek diagnostic catheter & $\begin{array}{l}\text { Alternatives strategies are the use of multiple guidewires and } \\
\text { balloon-anchoring technique. We usually associated a rotation } \\
\text { ipsilateral to the common carotid and sometimes we change } \\
\text { the Vitek catheter for a vertebral diagnostic catheter once the } \\
\text { guiding catheter is engaged in the target supra-aortic vessel. }\end{array}$ \\
\hline Left carotid stroke & Coaxial technique with Vitek diagnostic catheter & When this feature is isolated it is not particularly challenging. \\
\hline
\end{tabular}




\section{Techniques for challenging supra-aortic access}

In most patients, our first-line choice for anterior circulation LVO is a transfemoral approach (TFA) coaxial technique consisting of a $125-\mathrm{cm} 5 \mathrm{~F}$ Vitek diagnostic catheter (VDC; Cook ${ }^{\mathrm{TM}}$, Cook Medical, Bloomington, IN, USA) over a 9F balloon guide catheter (BGC) to avoid an exchanging maneuver. Initially, we engage the VDC in the proximal supra-aortic vessels and gently advance a hydrophilic 0.038" guidewire in the ICA (Figure $3 \mathrm{~A}$ ). The BGC can often be advanced over the guidewire with the VDC at the level of the proximal supra-aortic vessels (Figure 3B). In other cases, we first have to navigate the VDC into the ICA and finally advance the BGC over the VDC/hydrophilic guidewire (Figure $3 C, D$, and $E$ ). In cases of more severe tortuosity, we initially achieve cervical access using the distal exter-

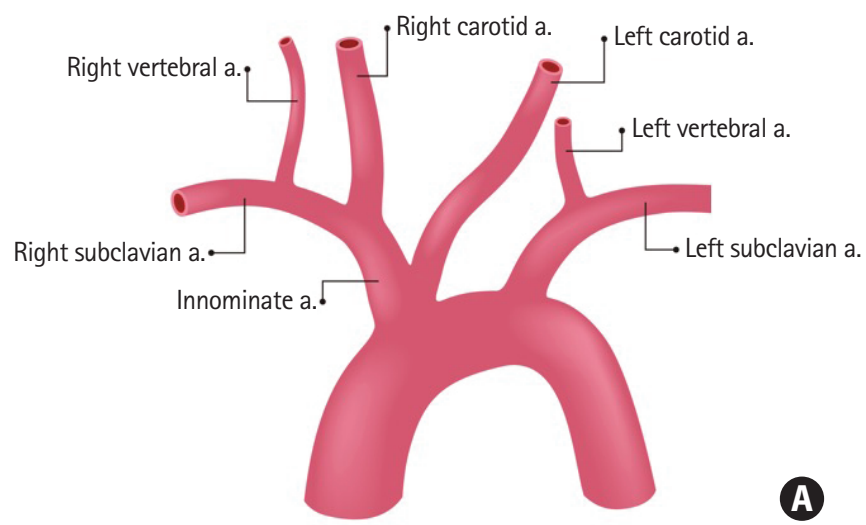

nal carotid artery (ECA) for safer and better mechanical support.

In cases with an associated proximal angulation at the first third of the CCA, the distal progression of the guidewire and VDC may be challenging. If it is possible to advance the guidewire distal to this curve, we try to gently to insert the BGC in the take-off of the great vessel of interest and maximally inflate the BGC at the origin of the brachiocephalic trunk or left CCA to provide anchoring to support the distal navigation of the guidewire and VDC (Figure $3 \mathrm{~F}$ and $\mathrm{G}$ ). Finally, the balloon is deflated and the BGC is advanced over the VDC (Figure $3 \mathrm{H}) .{ }^{26}$ In some situations, the hook of the VDC hampers its progression into the CCA. In these cases, the VDC can be used to catheterize the innominate or left CCA and an exchange-length

Figure 1. Some situations impose more challenges for supra-aortic access during mechanical thrombectomy and should be promptly identified: (A) a common origin for the innominate and left common carotid arteries (CCAs), (B) the left CCA originates from the innominate artery. a., artery.

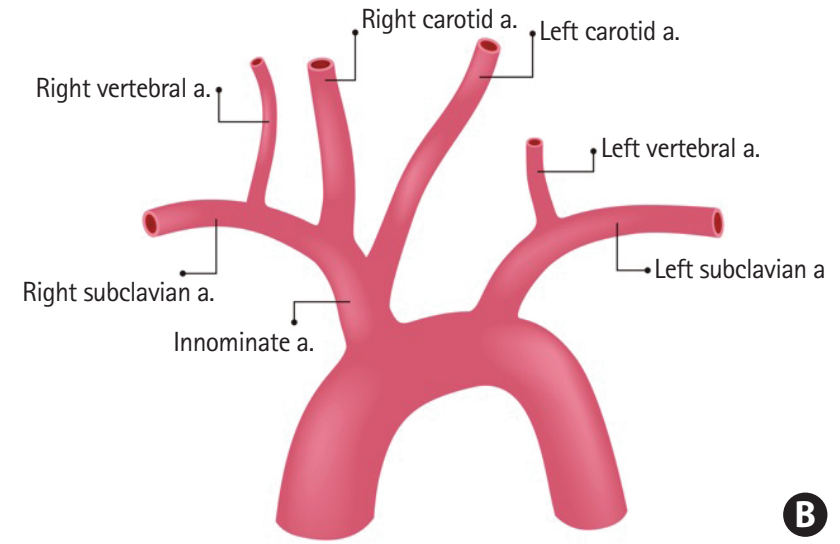

B

Type 1

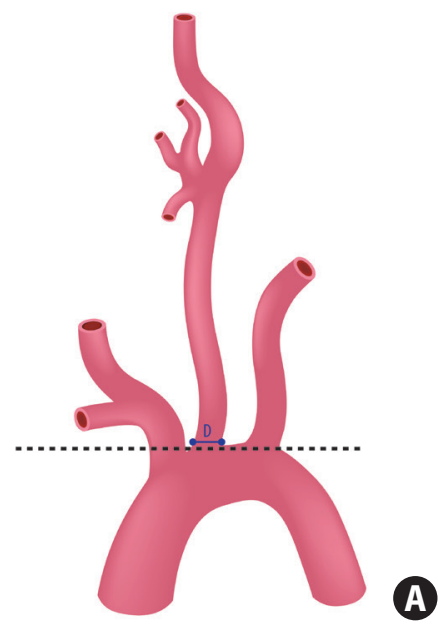

Type 2

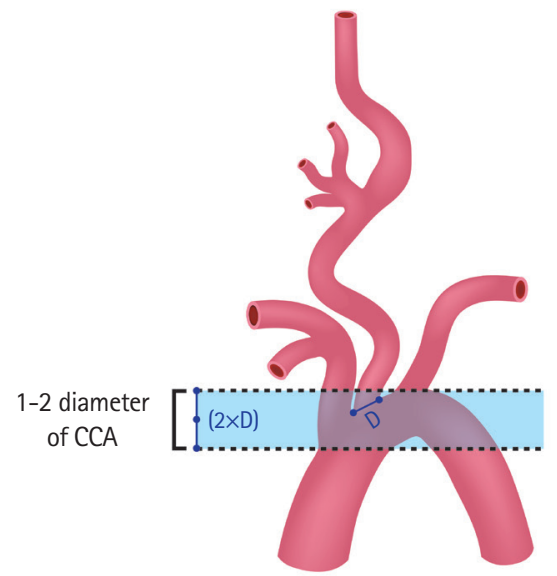

Type 3

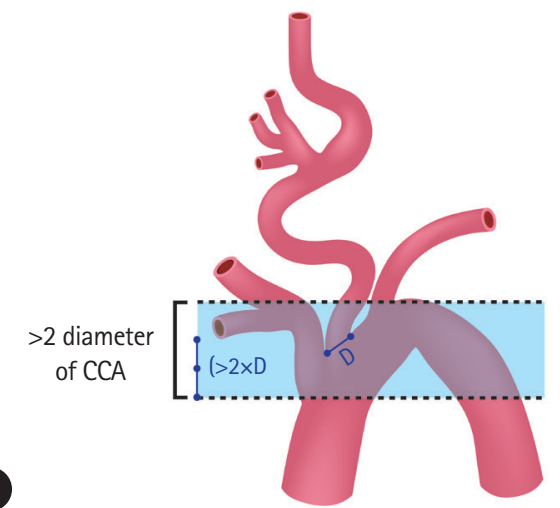

Figure 2. Aortic arch configurations. Type 2 and 3 aortic arch may be obstacles for rapid supra-aortic access. The vertical distance from the origin of the innominate artery to the top of the arch determines the arch type. This distance is $<1$ diameter of the left common carotid artery (CCA) in a type 1 arch (A), between 1 and 2 diameters of the left CCA in a type 2 arch (B), and $>2$ diameters of the left CCA in a type 3 arch (C). 

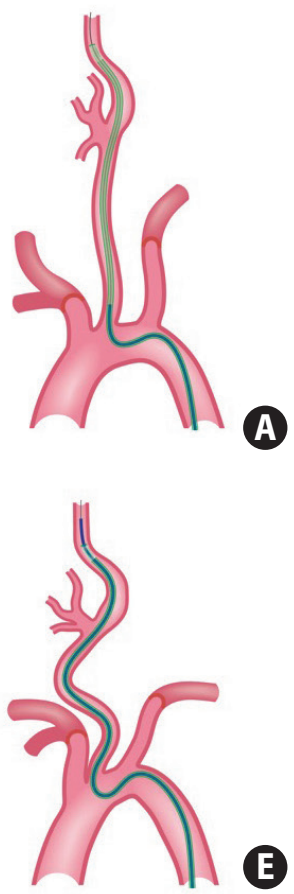
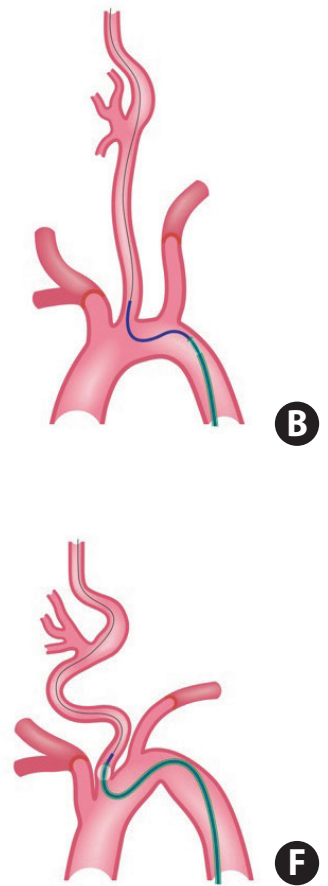
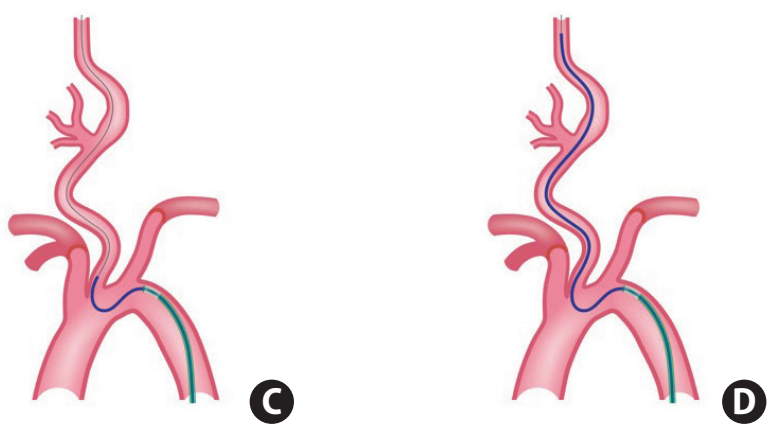

D

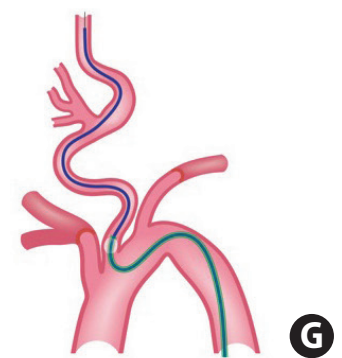

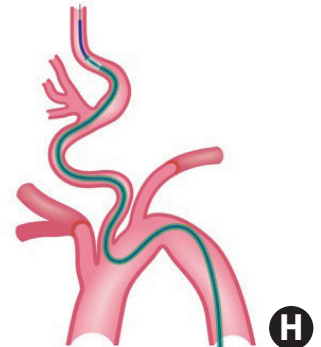

Figure 3. Strategies for supra-aortic access using coaxial technique with a 125-cm 5F Vitek diagnostic catheter (VDC; blue) over a 9F balloon-guiding catheter (BGC; green) to avoid an exchanging guiding maneuver. (A) VDC engaged in left common carotid artery then a hydrophilic 0.035 " or 0.038 " guidewire is advanced in the internal carotid artery (ICA). (B) BGC can be advanced in the ICA over the guidewire while the VDC is still at the origin of the proximal supraaortic vessel. (C) In case of severe proximal tortuosity first VDC is engaged, then the guidewire is progressed distally, after that (D) VDC is navigated over the guidewire into the ICA and finally the BGC is advanced over the VDC/guidewire (E). In case of more proximal angulation with a short proximal segment of CCA for engagement, BGC is initially advanced in the proximal CCA over the VDC, then it is maximally inflated to stabilize (F). Once the support is ensured, a guidewire and VDC are sequentially advanced more distally (G). Finally, the balloon is deflated, and the BGC is advanced over the VDC (H).

guidewire can be used to exchange the VDC for a less angled catheter such as a vertebral catheter, which can more easily navigate the cervical segments (Figure 4).

When this is not feasible, the use of multiple parallel guidewires is another alternative. ${ }^{27}$ With this technique, we engage the supra-aortic vessel of interest with the diagnostic catheter to individually advance 2 to 3 micro-guidewires (0.014" or $0.018 ")$ as distal as possible into the CCA, ECA, or ICA. After all guidewires are in place, the diagnostic catheter is advanced into the distal cervical vessel of interest and we finally advance the guiding catheter into the target cervical vessel (Figure 5).

Another option that may be used, although rarely, is the use of a balloon-anchoring technique. ${ }^{28}$ Once the proximal supraaortic vessel is engaged, an aneurysm remodeling balloon is advanced distally over a 0.014 " guidewire, either in the ECA or ICA, and is inflated and anchored to allow for the subsequent progression of the guiding catheter and BGC.

In cases with proximal angulation in the origin of the left CCA, we have observed that a cervical rotation to the right side plus cervical extension may straighten the vessel and facilitate guidewire and guiding catheter navigation.
Despite the aforementioned techniques, the TFA may still fail or the attempts may be too time-consuming. Ribo et al. ${ }^{14}$ reported a better angiographic and clinical outcome in patients with a time from femoral artery puncture to cervical access of less than 20 minutes compared to that in patients with an access time of longer than 30 minutes. Thus, in our routine practice, we use 15 minutes for cervical access as a benchmark to proceed to alternative routes. Naturally, if pre-procedural evaluation by CT angiography (CTA) identifies any major anatomical hurdles (Table 1, e.g., combination of type III aortic arch severe, angulation of the proximal CCA, and tandem occlusion), we bypass the TFA in favor of an alternative arterial access.

\section{Alternative routes for challenging supra-aortic access}

\section{Transradial access}

Transradial access (TRA) for neurointerventional procedures has gained increased interest for procedures in both anterior and posterior circulation. The technique for radial access has been described in detail elsewhere. ${ }^{29}$ The right radial artery is used in 

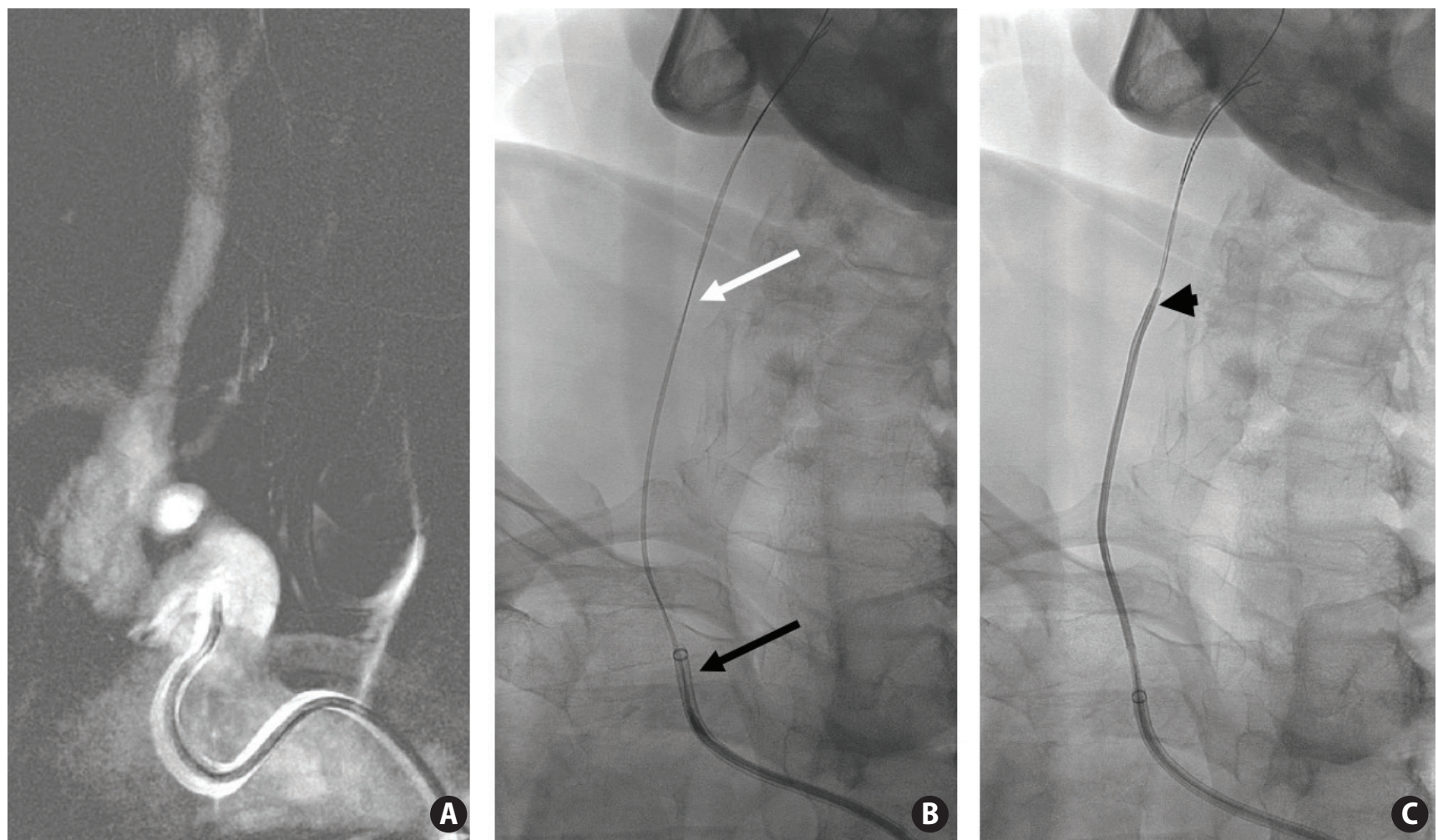

Figure 4. Changing the curvature of diagnostic catheter in coaxial technique is an option to achieve supra-aortic access. (A) Brachiocephalic trunk injection with a Vitek diagnostic catheter in coaxial system with a Neuron ${ }^{\mathrm{TM}}$ MAX 088 shuttle (Penumbra Inc.) depicting an extreme tortuosity that was an obstacle for progression of the guiding catheter. (B) A Neuron ${ }^{T M}$ MAX 088 shuttle was placed at the origin of supra-aortic vessel (long black arrow) and three 0.014 " exchange wires were consecutively advanced (long white arrow). (C) Once a stable support was obtained, a 6F diagnostic catheter with a Berenstein curve (black

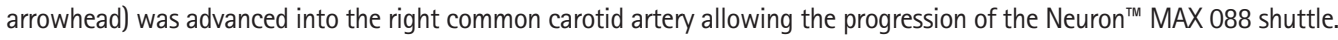

most cases, except when the left vertebral artery is the only vessel to be catheterized, for which left-sided radial access is preferable. After radial puncture, a cocktail of prophylactic spasmolytic agents (5 $\mathrm{mg}$ verapamil or $200 \mu \mathrm{g}$ nitroglycerin or 3 to $5 \mathrm{mg}$ milrinone) plus 1,000 units of heparin in $20 \mathrm{~mL}$ of saline is infused through the dilator. An angiogram can be performed but often a round non-traumatic "J" tip wire can be safely advanced into the subclavian artery in a blind manner. If no anatomic obstacle is detected, a 6F Long Sheath (Flexor Shuttle-SL ${ }^{\mathrm{TM}}$, Cook; Neuron ${ }^{\mathrm{TM}}$ MAX 088 Shuttle, Penumbra, Alameda, CA, USA; Benchmark ${ }^{\text {TM }}$ 071, Penumbra; AXS Infinity LS Long Sheath ${ }^{\mathrm{Tm}}$, Stryker, Kalamazoo, MI, USA; Ballast ${ }^{\mathrm{TM}} 088$ Long Sheath, Balt, Irvine, CA, USA) is advanced over the Rosen wire. The choice of catheter configuration for navigating the aortic arch vasculature depends on the patient's specific anatomy and the vessel to be catheterized but we typically start with a Simmons $2 .^{29}$

Besides providing access in cases in which TFA techniques are not feasible, a major benefit of the TRA is a low rate of access site complications, including hematoma and pseudo-aneurysm formation, for which TRA has been associated with lower mortality rates..$^{30}$ However, the TRA approach has some limitations. First, due to the small size of the radial artery, $y_{1}^{29,31,32}$ there is typically a limitation to the use of a 6-Fr sheath, which typically prevents the utilization of BGC shown to be more effective in MT than conventional guiding catheters in both stent-retriever (SR) and contact aspiration (CA) treatment modalities. ${ }^{33}$ Second, navigating the aortic arch from the right TRA requires different skills than those required when navigating the same vessels from TFA. A significant learning curve is required and a cut-off of 30 to 50 procedures has been proposed for the full optimization of procedural performance. ${ }^{34}$ Third, vascular anatomical variations in the upper limb (radial artery tortuosity, stenosis, hypoplasia, radioulnar looping) may be present in up to $10 \%$ of cases and may preclude catheter progression in 2\% of cases (Figure 6). ${ }^{32}$ Finally, the specific configuration of the supra-aortic vessels may be prohibitive for navigating catheters and lead to technical failure in $4 \%$ of cases. ${ }^{32}$ This technical challenge may be observed when the right CCA arises from the right subclavian artery at a very acute angle or when the right CCA ostium is close to the aortic arch, favoring catheter herniation into the arch. The decision to use TRA or 

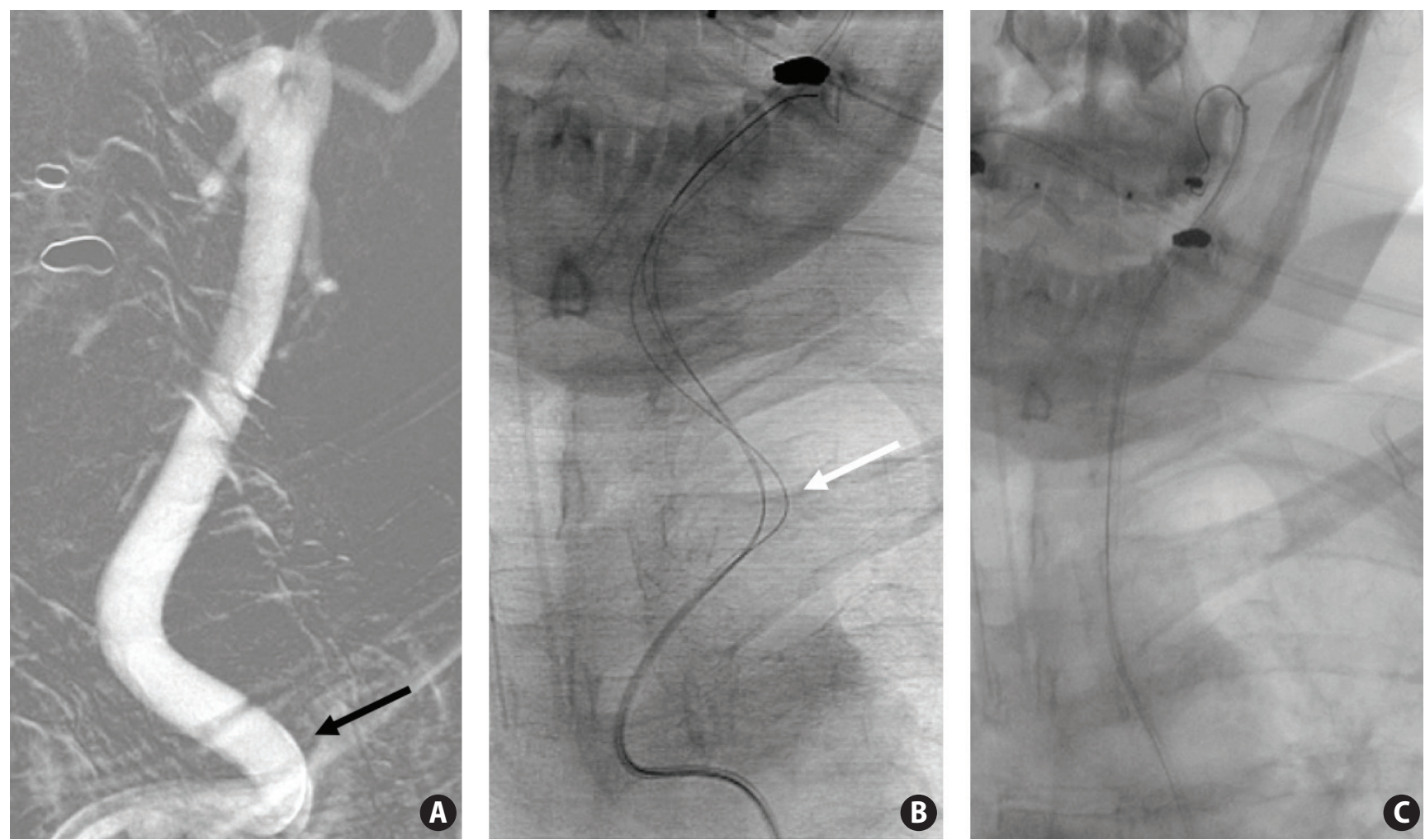

Figure 5. Use of multiple guidewires in very tortuous extracranial vessel access. (A) Anteroposterior roadmap view of left common carotid artery depicting a recurrent origin at the aortic arch and a proximal angle turn after its origin (long black arrow), precluding advance of 0.035" guidewire. (B) Three 0.014" guidewires were navigated one after the other (long white arrow), (C) allowing enough support for progression of the guiding catheter.

TFA is not standardized in most services but it is advisable to use TRA in the following situations: unfavorable iliofemoral and aortic anatomy ( $>20$ minutes from groin puncture to target cervical artery), posterior circulation stroke, and extreme vascular tortuosity in pre-procedural CTA. An excessive delay in the decision to switch from a TFA to TRA may result in worse outcomes. ${ }^{35}$

TRA may be used as a first approach in posterior circulation stroke, mainly in elderly patients; however, the vertebral artery must be assessed in baseline neuroimaging (e.g., the CTA) because it may preclude a swift approach; for example, when the origin of the vertebral artery is in the aortic arch or close to the take-off of the subclavian artery in the aortic arch. The more direct navigation into the posterior circulation and more stable position of the guiding catheter as compared to the TFA may result in shorter recanalization times. In posterior circulation strokes treated with MT, the advance of large-bore BGC is typically restricted regardless of the type of access (TRA or TFA) due to the smaller size of the vertebral artery compared to that of the carotid artery and the inability to achieve full flow control (due to the contralateral vertebral artery). Thus, the use of TRA for CA alone or combined with SR may be specifically advantageous. Maud et al. ${ }^{36}$ recently evaluated their initial expe- rience of MT in posterior circulation stroke using TFA or TRA. TRA was as effective and safe and was 35 minutes faster than TFA. ${ }^{36}$

Regarding the use of TRA for MT in anterior circulation, most authors have demonstrated successful recanalization $(\mathrm{TICl} \geq 2 \mathrm{~b}$ ) in up to $90 \%$ of patients in an expeditious fashion, even though the use of BGC is typically not possible in this situation. ${ }^{35-38}$

\section{Transbrachial access}

Transbrachial access has been proposed as a potential route for endovascular treatment as the larger caliber of the brachial artery offers the advantage of allowing the use of large-bore catheters (up to 8 to $9 \mathrm{~F} \mathrm{BGC).} \mathrm{The} \mathrm{major} \mathrm{drawback} \mathrm{is} \mathrm{a} \mathrm{higher}$ risk of site complications (12\% to 16\%) including compressive hematoma/compartmental syndrome, pseudoaneurysm, and brachial artery occlusion. Thus, careful patient selection and proper technique are paramount. The number of puncture attempts may have some influence on the frequency of complications, especially if the patient has received intravenous tissue plasminogen activator (IV tPA). ${ }^{39-43}$

In our practice, this is a very rare option used in cases of posterior circulation stroke with very tortuous aortic arch and 


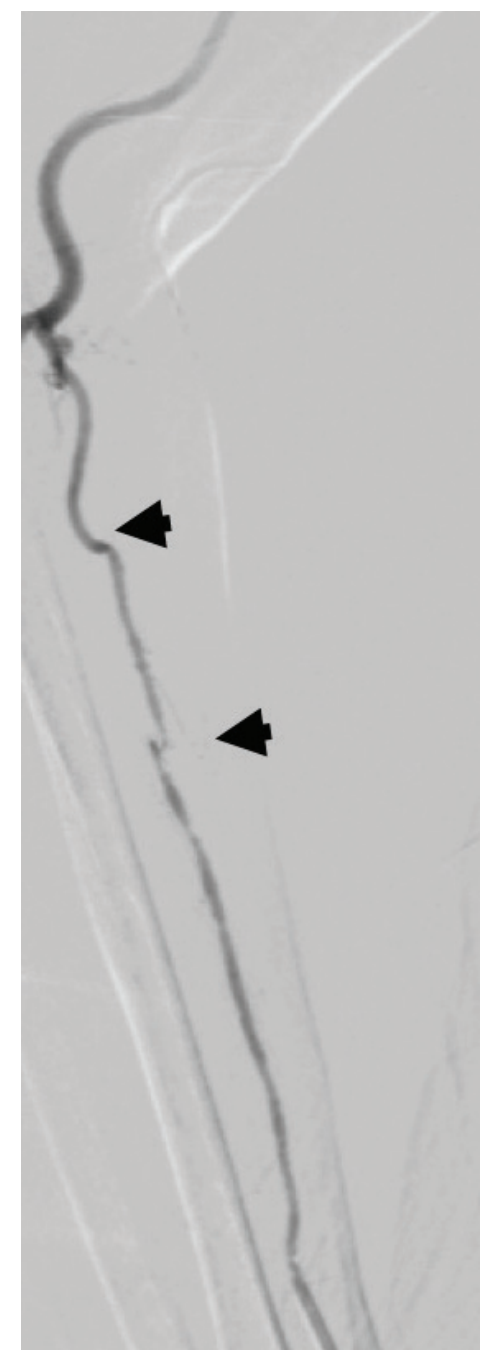

Figure 6. Right radial angiogram depicting a hypoplasia of right radial artery with associated tortuosity (black arrowheads), preventing the use of this route for mechanical thrombectomy.

subclavian looping, as assessed by CTA or transfemoral angiography, and only in the setting of vascular anomalies of radial artery that prevent catheter progression. From a technical point of view, the brachial artery is accessed above the biceps tendon, ideally using a micropuncture set after a palpable brachial artery pulse and under ultrasound guidance. It is important to mention that, in comparison to the radial and femoral arteries, the brachial artery rolls considerably more, forcing the operator to fix the artery firmly with the fingers while the needle is advanced. We otherwise follow the same steps as for guiding catheter progression in TRA. However, the use of vasodilators is not required.

Case series using the transbrachial approach for the endovascular treatment of AIS suggest that it is a feasible technique and may be considered as an alternative route, particularly in patients with posterior circulation strokes. . $^{3941,43}$

\section{Direct carotid puncture}

When facing unfavorable vascular anatomy during the endovascular treatment of AIS, direct carotid artery access (DCA) is an alternative strategy that provides rapid access to anterior circulation. ${ }^{4-46}$

Some authors argue that this technique must be the first option after TFA failure in patients with anterior circulation stroke and anatomical variants associated with technically challenging carotid access. Others claim that TRA access should be preferred as a first-line option. ${ }^{43}$

In their review, Mokin et al. ${ }^{45}$ provided a detailed description of techniques. They favored the use of ultrasound to visualize and punctured the carotid artery 3 to $4 \mathrm{~cm}$ above the clavicle using a 21-gauge micropuncture needle at a $45^{\circ}$ angle. We have also found that it is often feasible to engage the Vitek catheter at the origin of the greater vessels and obtain a roadmap angiogram that may further facilitate puncture of the carotid artery under ultrasound guidance (Figure 7A and B). A puncture close to the clavicle makes access difficult since the needle will have a perpendicular entry angle into the CCA. As the carotid artery may roll during the advance of the needle, it is advisable to fix it between fingers. Once the carotid is punctured, a 0.014 " to 0.018 " micro-guidewire is advanced under fluoroscopy. A 5-Fr dilator is placed over the microwire, the microwire is removed, and a roadmap is performed. Under roadmap guidance, a 0.035 " guidewire is inserted, over which a 6 - Fr sheath is placed. When $6 \mathrm{~F}$ sheath access is established, distal access to ICA is achieved using an aspiration catheter, and we favor the use of direct aspiration or combined technique for MT (Figure 7C-F).

In the literature, DCA is used in about $2.2 \%$ to $4.6 \%$ of all MT, mostly in the left CCA. Endovascular treatment using DCA is as effective as TFA. One series described technical failure to achieve carotid access in one of 11 patients ( $9.1 \%$ of cases) while successful recanalization was identified in eight of 10 $(80 \% \text { of cases) })^{45,46}$

The main downside of this technique is access complications $(11 \%)$ including carotid dissection and neck hematoma. ${ }^{44,46,47}$ Large cervical hematomas can be life-threatening, so attention should be given to achieving hemostasis at the puncture site, especially after the use of intravenous thrombolysis. If engagement of a Vitek catheter at the origin of the greater vessels is possible, we recommend performing a control angiogram after sheath removal and hemostasis to exclude subclinical extravasation. Off-label use of arterial closure devices such as the Angio-Seal (St Jude Medical, St Paul, MN, USA) and StarClose SE Vascular Closure System (Abbott Vascular, Abbott Park, IL, USA) 

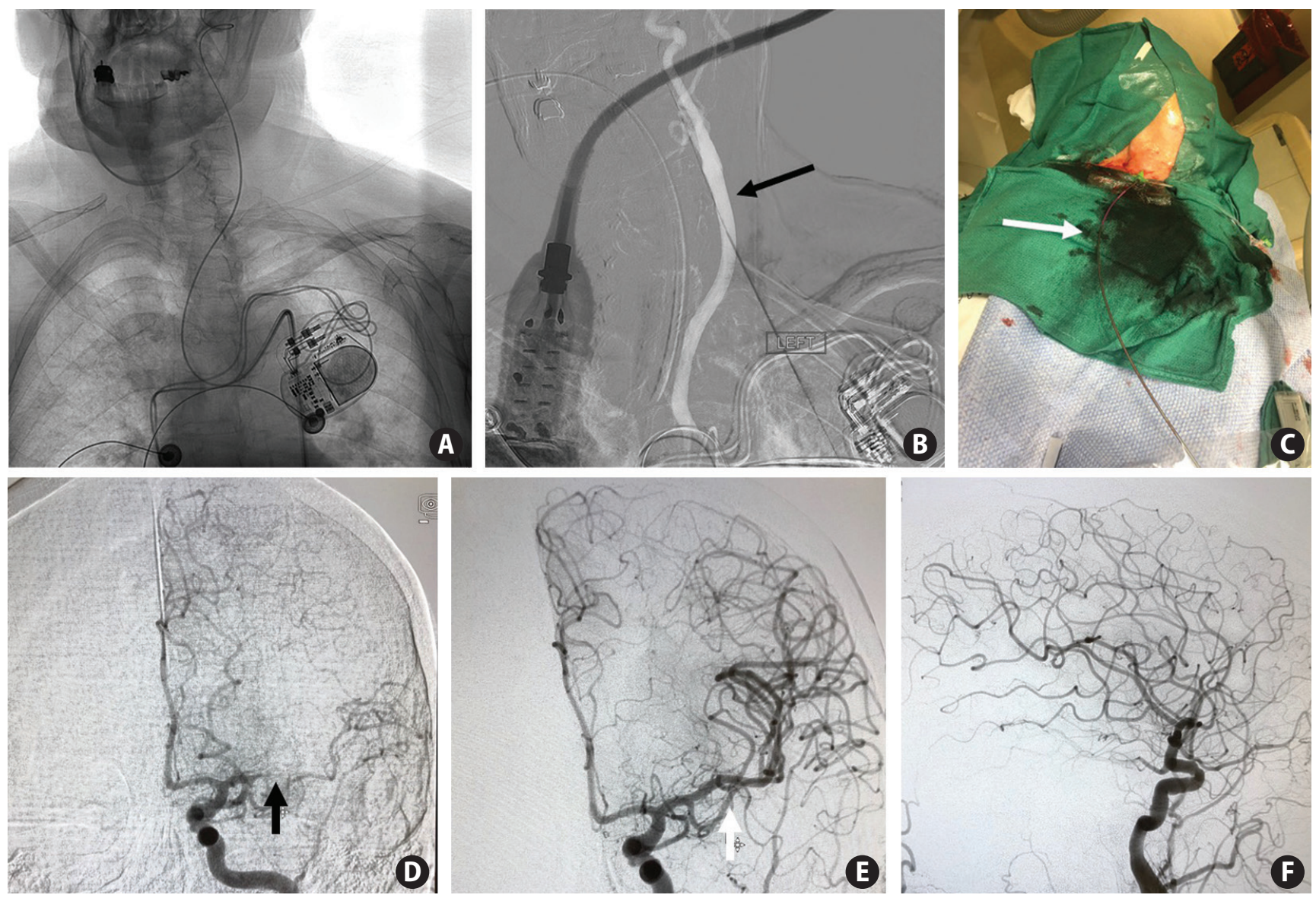

Figure 7. Direct carotid puncture is valuable option is very difficult aortic arch. (A) Anteroposterior acquisition of a recurrent left common carotid artery in type III aortic arch, preventing advance of a coaxial system guiding catheter over a hydrophilic guide wire. (B) Anteroposterior roadmap view for direct puncture guidance with a $18 \mathrm{G}$ needle (long black arrow) with concomitant use of an ultrasound. (C) A 6F sheath was placed in the left common carotid artery and an ACE 68 aspiration catheter (Penumbra Inc.) was advanced the internal carotid artery (long white arrow). (D) Selective anteroposterior carotid angiogram at the beginning of thrombectomy disclosing proximal M1 occlusion (short black arrow). Thrombectomy was performed using a combined technique (ACE 68 aspiration catheter; $4 \times 30 \mathrm{~mm}$ Trevo XP Stentriever, Stryker) allowing a thrombolysis in cerebral infarction (TICI) grade 3 reperfusion after one pass as shown in anteroposterior (short white arrow) (E) and lateral view (F). After procedure, we retrieved the sheath and closed the punctured site by manual compression.

have been reported. ${ }^{44,47}$ However, there are some concerns regarding such use of closure devices, including dissection, risk of arterial wall injury with pseudoaneurysm formation, dislodgement and embolization of the intra-luminal portion of the device into the intracranial arterial circulation, and inadequate closure with bleeding/hematoma formation. Conversely, leaving the sheath in place for extended periods awaiting reversal of anticoagulation or fibrinolysis carries a potential risk of embolization or dissection from the sheath itself.4,46,47

An alternative technique for DCA is transcervical access using a surgical cut-down approach. Wiesmann et al. ${ }^{48}$ described six cases of endovascular treatment of acute stroke involving combined surgical access to the carotid artery and carotid puncture. Intracranial recanalization was achieved in 100\% of cases; however, one patient (16.6\%) developed a small neck hematoma that was surgically removed without further complications. It is important to acknowledge that this more com- plex approach is time-consuming and may be particularly unsuitable for patients with LVO strokes after IV tPA. ${ }^{48}$

\section{Unfavorable vascular anatomy in cervical arteries}

Morphological anomalies of the cervical ICA are associated with cerebrovascular diseases and may represent a significant challenge to the endovascular treatment of cervical and intracranial diseases. While the prevalence of these deformities varies according to the morphological criteria and the diagnostic techniques used, they are identified in up to $85.8 \%$ of patients. ${ }^{49}$ Nagata et al. ${ }^{49}$ considered an ICA to be tortuous if the angle between the CCA and the ICA centerlines was $>15^{\circ}$ or if the course of the ICA was S- or C-shaped. ICA was considered straight if the angle was $<15^{\circ}$. ICA morphology was further classified as coiling (an exaggerated S-shaped curve or a circu- 


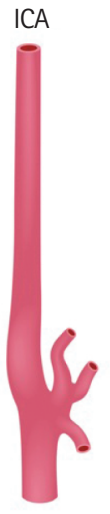

Staight

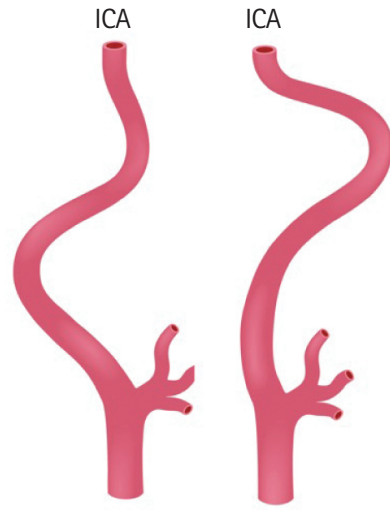

Tortuosity

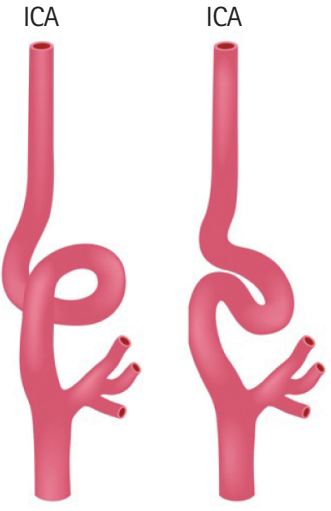

Coiling

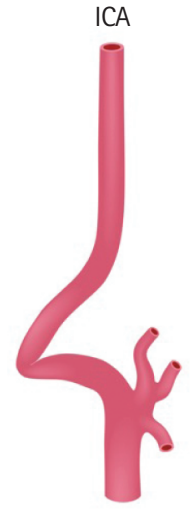

KinKing

Figure 8. Tortuous vascular anatomy impairs the optimal positioning of the guiding catheter and subsequent distal progression of catheters. We should identify variations of carotid artery that may be a barrier to distal cervical and intracranial access like coiling and kinking. Modified of Nagata et al. ${ }^{49}{ }^{\text {with }}$ permission from Elsevier. ICA, internal carotid artery.

lar configuration; 3.0\% of cases) or kinking (angle between vessel segments $<90^{\circ}$ and associated with stenosis; $1.0 \%$ of cases) (Figure 8). ${ }^{49}$

Such deformities may be related to congenital (e.g., fibromuscular dysplasia) or acquired diseases. In general, vascular abnormalities are acquired and associated with atherosclerosis risk factors such as hypertension, hyperlipidemia, and smoking. The prevalence of vessel elongation increases with age and is thought to be related to the loss of elasticity with aging. ${ }^{50}$

Elongation of the ICA in the neck is generally not a major obstacle during MT with appropriate positioning of the guiding catheter. However, some anatomic difficulties beyond elongation and extreme tortuosity may be present, including kinking and coiling, which may influence the chances of successful recanalization.

Tortuous cervical anatomy may preclude the optimal positioning of the distal access or intracranial aspiration catheters and/or BGC, which can then herniate back into the aortic arch during the subsequent attempt to achieve intracranial access. Indeed, a BGC position below the lower margin of the $\mathrm{C} 1$ vertebral body and the presence of carotid tortuosity have been associated with lower recanalization rates with SRs. ${ }^{25}$ This might be related to the risk of access loss due to an unstable catheter position or less efficient aspiration. The petrous segment of the ICA is firmly attached to the petrous bone as opposed to the extracranial ICA, which is surrounded by soft tissue. Thus, aspiration through the BGC, when located proximally, increases the risk of arterial collapse, which attenuates the clot removal force while also favoring distal emboli. ${ }^{25}$

Stratification of patients with technically difficult cervical access during MT is critical as it allows for a better selection of devices and alternative strategies at an early stage of the procedure (Table 2).

\section{Techniques for challenging cervical arteries}

Some techniques may be used to overcome cervical vascular tortuosity. ${ }^{51-53}$ Due to the evolving technology of materials for MT, nowadays is feasible to navigate a large-bore catheter $(0.074 ")$ in the intracranial circulation. These newer-generation catheters anchor around vascular bends as they pass the proximal curve and it may be possible to use them as support for distal vessel progression. The ideal catheter would have trackability that requires the minimum force applied by the operator to progress over the successive curves. Aspiration capability and the ability to deliver other devices such as SRs, angioplasty balloons, and self-expanding or balloon-mounted stents should also be considered during the selection of appropriate catheters. $^{51}$

A drawback of distal access-guiding catheters (or intermediate catheters [ICs]) is the lack of proximal support. The most significant reported complication of ICs is asymptomatic vasospasm, which occurs in 3.3\% of cases. ${ }^{52}$ Turk et al..$^{53}$ reviewed the use of ICs in neuroendovascular treatment and reported a complication rate of $1.4 \%$, including $1 \%$ with arterial dissection (Figure 9).

ICs may be used either for direct aspiration or as a conduit for SR. The use of IC for MT allows easy negotiation of tortuosity in cerebral vessels or distal cervical segments of the vertebral and carotid arteries, providing adequate stability for microcatheter vessel selection into intracranial vasculature. ICs also straighten the cervical and intracranial access, which facilitates SR removal by ensuring a more favorable vector for 
Table 2. Features related to challenging cervical and intracranial route

\begin{tabular}{|c|c|c|}
\hline Unfavorable vascular features & Initial operative strategy & Observation \\
\hline ICA dolichoarteriopathy & Intermediate catheter & At operator discretion it can be used a combined technique with stent-retriever. \\
\hline Carotid siphon tortuosity & Intermediate catheter & At operator discretion it can be used a combined technique with stent-retriever. \\
\hline Curved MCA (or curved target vessel) & Intermediate catheter & $\begin{array}{l}\text { Initial option should be direct aspiration. } \\
\text { In case no aspiration catheter is available a double stent-technique may be an ac- } \\
\text { ceptable option either in parallel or in } \mathrm{Y} \text { configuration. }\end{array}$ \\
\hline Clot placed in a bifurcation & Intermediate catheter & $\begin{array}{l}\text { Initial option could be either stent-retriever or contact aspiration. } \\
\text { In case of failure of both stent-retriever and contact aspiration a Y stent-technique } \\
\text { may be an acceptable option. }\end{array}$ \\
\hline
\end{tabular}

ICA, internal carotid artery; MCA, middle cerebral artery.

retrieval force, thus optimizing the MT results. ${ }^{54}$

If pre-procedural CTA evaluation reveals extreme tortuosity in the supra-aortic vessels that will be an obstacle for catheterization of supra-aortic vessels and guide catheter positioning, we favor the use of a base catheter such as the Neuron ${ }^{\text {Tm }}$ MAX, Benchmark ${ }^{\mathrm{TM}}$, or Chaperon ${ }^{\mathrm{TM}}$ (Microvention, Aliso Viejo, CA, USA), together with local aspiration either alone or in combination with SR. If the initial CTA assessment shows that navigation of a BGC is feasible, we use it with an IC to overcome tortuosity of cervical arteries and proceed with local aspiration alone or combined technique (Table 2).

\section{Unfavorable vascular anatomy in intracranial arteries}

Unfavorable vascular anatomy not only affects the ability and speed to access a cervical position but may also interfere with access from the cervical segment to the culprit lesion, device delivery, and clot retrieval.

The tortuosity of intracerebral arteries may affect the mechanics of both SR and CA devices. During MT with SR, the retrieval force vector $\left(F_{R}\right)$ applied during the device pull-back is dispersed since there will be a decomposition of the original vector of force applied in the retriever wire in at least two components; namely, $F_{R}$ effective towards the required motion direction to displace the $S R$ from the target vessel and an $F_{R \text { detri- }}$ mental perpendicular to the $F_{R}$ effective. The magnitude of the effective retrieval force $\left(F_{R}\right.$ effective $)$ in each tortuous vessel will be proportional to the cosine of the angle between the segments involved in the device movement. In other words, this angle is measured between the vessel segment conterminous to the occlusion site and the segment immediately proximal to it (Figure 10). Thus, a traction force applied in an angled artery will create not only an optimal component along the axis of the occluded artery ( $F_{R}$ effective $)$ but also a detrimental vertical component of force perpeicular to the artery $F_{R}$ detrimental that, in some instances may be more significant than $\mathrm{F}_{\mathrm{R} \text { effective (compare }}$ Figure $10 \mathrm{~A}$ and $\mathrm{B}$ ). In very curved arteries, the SR will be stretched during the retrieval process, resulting in lower wall apposition and constriction of the stent cell size, which may lead to a loss of interaction with the clot. Consequently, the clot may escape from the stent. ${ }^{55-57}$ This effect has been described as a "tapering" phenomenon (Figure 11). ${ }^{55}$

Data highlighting the deleterious impact of intracranial tortuosity on the efficacy of revascularization dates back from the early times of MT. Zhu et al. ${ }^{57}$ classified M1 and M2 vessel susceptibility signs on baseline MRI in patients that underwent treatment with the Merci Retriever Device (Concentric Medical Inc., Mountain View, CA, USA). Clot location on curved or branching vessels (irregular susceptibility vessel signs) was the only independent predictor of unsuccessful recanalization. ${ }^{57}$ Similarly, Yamamoto et al..$^{56}$ observed a negative effect of vessel angulation on successful recanalization using the Merci Retrieval System. ${ }^{56}$ The authors measured the angle formed by the $\mathrm{M} 1$ segment of the middle cerebral artery (MCA) and ICA on conventional angiography and demonstrated that an archtype M1 segment was a predictor of recanalization failure.

More recently, Schwaiger et al. ${ }^{55}$ assessed the effect of intracranial vessel angulation (ICA/MCA-M1, proximal MCA-M1/ distal MCA-M1, and proximal MCA-M2/distal MCA-M1 angles) on recanalization with SR. Patients with recanalization failure had higher intracranial vessel angulation. Notably, ICA/MCAM1 angle $<100^{\circ}$ was associated with successful recanalization using SR (sensitivity, 0.81 ; specificity, 0.88 ; Youden's J=0.69).

Intracranial tortuosity hinders the performance of both SR and CA techniques. Bernava et al. ${ }^{58}$ recently established that an angle of interaction between the aspiration catheter and clot of $\geq 125.5^{\circ}$ as a significant predictor of successful clot retrieval. As such, in face of severe intracranial tortuosity, it may be advantageous to place the CA catheter more distally to achieve a position as close to the same axis of the occlusive clot as possible to optimize the retrieval force. 

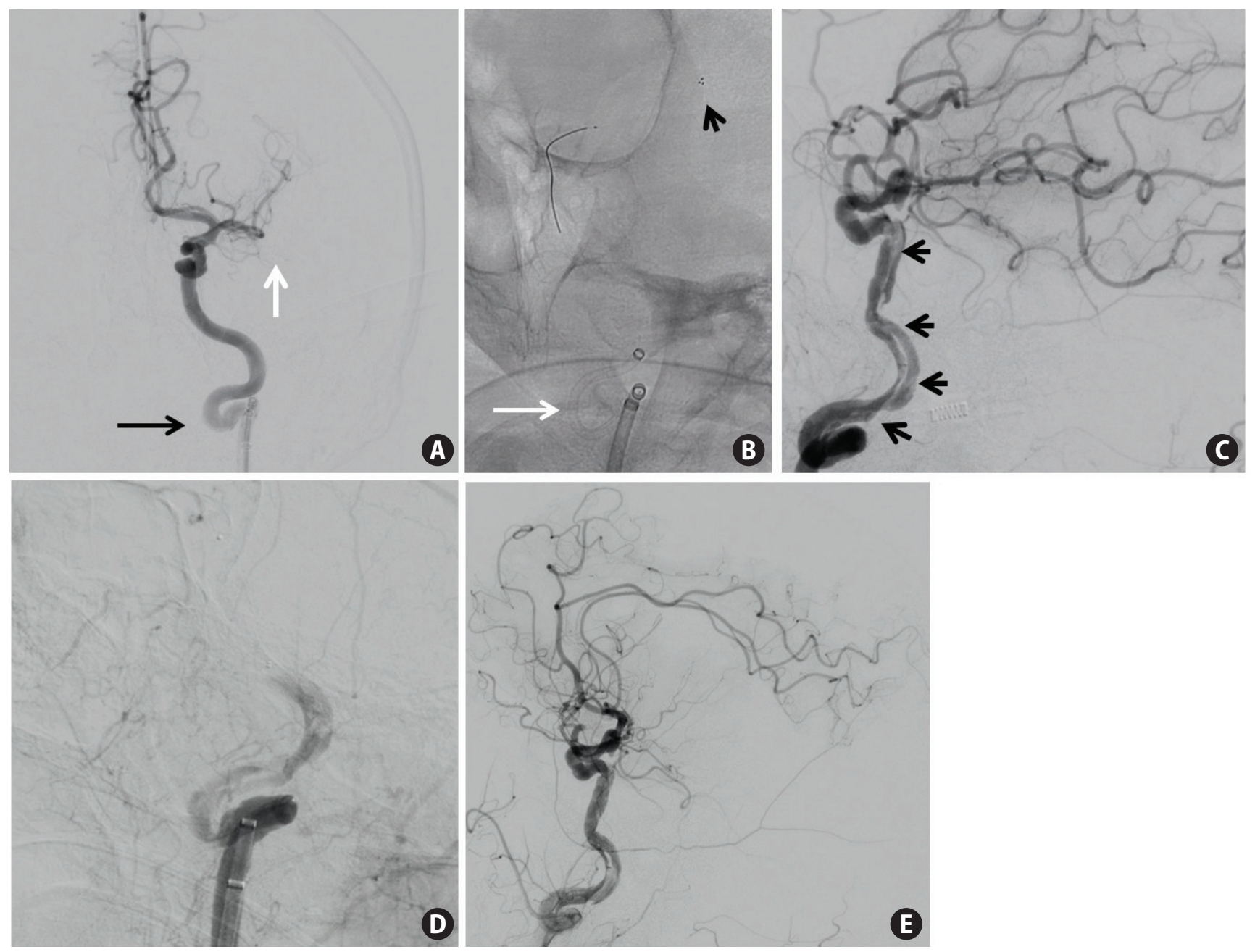

Figure 9. A 65-year-old man with left middle cerebral artery (MCA). (A) Left anteroposterior internal carotid angiogram through an 8F balloon-guiding catheter (BGC) shows a M1 occlusion (short white arrow) and a looping in the mid-cervical segment of internal carotid artery (long black arrow) that precluded the advance of the BGC. (B) An aspiration catheter (long white arrow) was used but it could not be advanced distally due to instability and low position of the BGC. A Solitaire stent-retriever (Medtronic) $4 \times 40 \mathrm{~mm}$ was then deployed over the clot (black arrowhead). (C) Lateral view of internal carotid artery (ICA) discloses a long dissection in the internal carotid artery (black arrowheads). (D) Oblique view of ICA shows a carotid occlusion at the level of dissection. (E) ICA was remodeled with two flexible stents but control angiogram of ICA M1 segment was occluded and was refractory to new attempts for revascularization (modified thrombolysis in cerebral infarction [mTICl] of 0).

Together, these clinical and anatomical variables should indicate a high-risk population for longer supra-aortic access time and difficult clot retrieval, allowing the operator to consider alternative access strategies or more appropriate MT techniques that may be pre-planned based on the evaluation of the baseline neuroimaging (Table 2).

\section{Techniques for challenging intracranial arteries}

\section{Carotid siphon}

Intracranial arterial tortuosity affects procedural complexity in neurointerventions, particularly those using SR, flow-diverters for intracranial aneurysms, and stenting for intracranial atherosclerotic disease. $^{59}$
Moniz defined the carotid siphon not as an anatomic region but rather as an angiographic sign. ${ }^{60}$ In 1982, the earliest classification of carotid siphon based on its geometry was proposed by Krayenbuehl and Yasargil. ${ }^{61}$ Carotid siphon tortuosity has been identified using several features, including (1) closed configuration of the anterior and posterior genu, resulting in an acute angle of the siphon; (2) exaggerated loops of the genus; and 3) a sharply sloping horizontal segment. ${ }^{61}$

These features were recently grouped in a four-grade classification system of carotid siphon tortuosity that considered the angles and height differences of the anterior and posterior genus from the top of the posterior genu the through of the anterior genu. Subsequent analysis of the procedural complexity for pipeline deployment showed a significant association with 

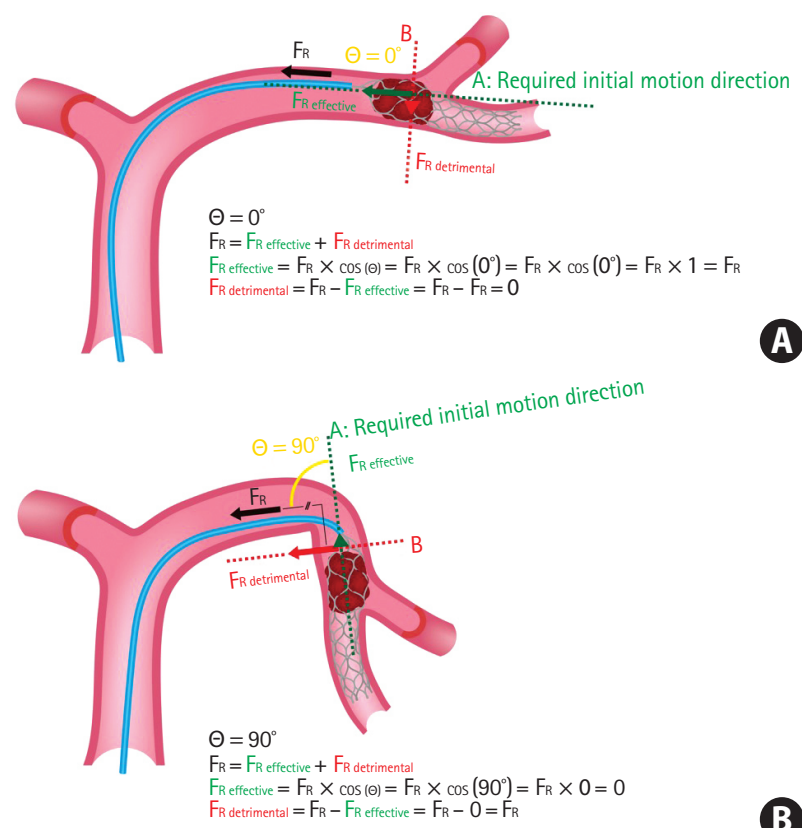

B

Figure 10. Decomposition of the original vector of force applied in the stent-retriever (SR) during mechanical thrombectomy. (A) Schematic representation of a M1 occlusion in a straight vessel. Vector decomposition during retrieval. The angle $\Theta$ (yellow) between the plan of the vector of retrieval force $\left(\mathrm{F}_{\mathrm{R}}\right.$, black) in $\mathrm{SR}$ and direction of required motion to displace the $S R$ (plan $A$, green) is $0^{\circ}$. The plan $B$ (red) is perpendicular to plan $A$, it creates a detrimental force to pullback ( $F_{\mathrm{R} \text { detrimental, }}$ red). The effective pullback force ( $F_{\text {R effective, }}$ green) will be towards the direction of the main axis of the occluded artery, in this situation equal to FR. Schematic representation of a M1 occlusion in a curved vessel. (B) Decomposition of vectors during retrieval, where the angle $\Theta$ (yellow) between $F_{R}$ in $S R$ and required direction of motion (plan $A_{1}$ green) is $90^{\circ}$. The $F_{R}$ effective in this case is the force required to displace the SR in the "diving" distal M1 segment that is towards

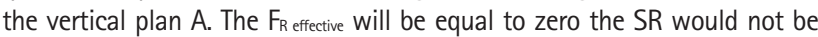
displaced and the $F_{R \text { detrimental }}$ is maximum and equal to $F_{R}$.

the degree of tortuosity (Figure 12). ${ }^{62}$

Assessment of the impact of carotid siphon configuration on outcome showed that the technical success rate was a function of siphon tortuosity, in which a more acute angle produced a higher the rate of technical difficulty for intracranial stenting. ${ }^{63}$ Similar challenges may be faced during the intracranial navigation of aspiration catheters for MT. In the presence of an acute siphon angulation, the aspiration catheter "lip" often gets caught at the edges of the carotid and/ or origin of the ophthalmic artery. In these cases, the association or replacement of the microcatheter for a larger coaxial catheter such as the Penumbra 3 MAX system may lead to the obliteration of this catheter "lip" and, potentially, some straightening of the vessel, allowing for successful distal navigation.

Another strategy involves the use of a compliant balloon (Scepter $\mathrm{C}^{\mathrm{T}}{ }^{\mathrm{M}}$, MicroVention/Terumo; or TransForm $\mathrm{C}^{\mathrm{TM}}$, Stryker
Neurovascular) in a coaxial system inside the large bore aspiration catheter to reduce the gap between the catheters, allowing easier navigation at the curvature of a tortuous artery. ${ }^{64}$ More recently, new and more cost-effective systems have been developed for this specific purpose, including the Scout Introducer and the AXS Offset Delivery Assist Catheter (both Stryker Neurovascular).

In cases of extreme tortuosity, some investigators have advocated the use of compliant balloons as an anchor to allow catheter progression..$^{65}$ Another way to overcome this situation is an anchoring technique using an SR. First, an SR is deployed over the clot for anchoring, then the aspiration catheter is pulled over the SR wire. A variation of this technique with "blind exchange" has been described for distal occlusions. ${ }^{66}$ Distal aspiration catheters (3 MAX ${ }^{\mathrm{TM}}$, Penumbra) are longer than microcatheters used during MT (160 cm vs. $157 \mathrm{~cm})$; thus, they cannot be navigated in a coaxial manner. In the blind exchange maneuver, an SR is deployed via a microcatheter; the microcatheter is then pulled out and a 3- or 4-MAX ${ }^{\mathrm{TM}}$ (Penumbra) aspiration catheter is gently advanced over the retrieval wire under fluoroscopy until clot contact. ${ }^{66}$ This technique can also be performed with larger aspirations systems in more proximal locations.

\section{Beyond the carotid siphon}

Significant intracranial tortuosity distal to the carotid siphon is another critical factor that reduces MT effectiveness; in particular, increased curvature of the carotid T and the MCA M1 and M2 segments impairs clot removal with MT using SR or CA. ${ }^{55-58}$

As a general rule, when intracranial vessel anatomy is deemed to be unfavorable, especially in the setting of a curved MCA or tortuous basilar artery, we tend to use CA either alone or in combination with SR. In case of failure or if an aspiration catheter is not available, another rescue therapy is the use of double parallel SRs to increase the force during the retrieval maneuver. ${ }^{67}$

Another potential vascular anatomy challenge is "saddle" clots positioned around bifurcation branches such as the MCA, carotid, or basilar bifurcations. In these situations, the clot may extend to both branches of the vessel and the surface of contact of the clot with the vessel will be higher. The consequent increase in friction force with the blood vessel wall requires increased retrieval force to displace the clot. When SR is the technique of choice for MT, one must consider that the SR must ideally be deployed in the larger branch for increased device interaction with the clot. Similarly, the more horizontal branch is preferred so that the retrieval vector force $\left(F_{R}\right)$ is more aligned with the device, improving the effective retrieval 


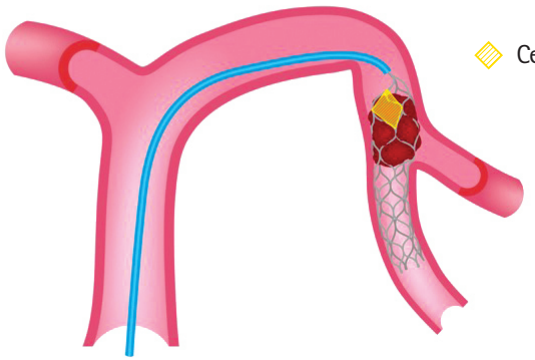

Cell size proportion

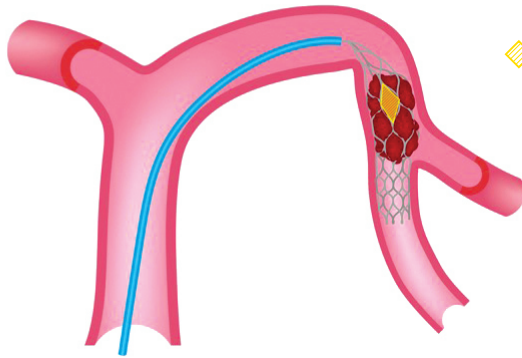

Cell size proportion

(A)
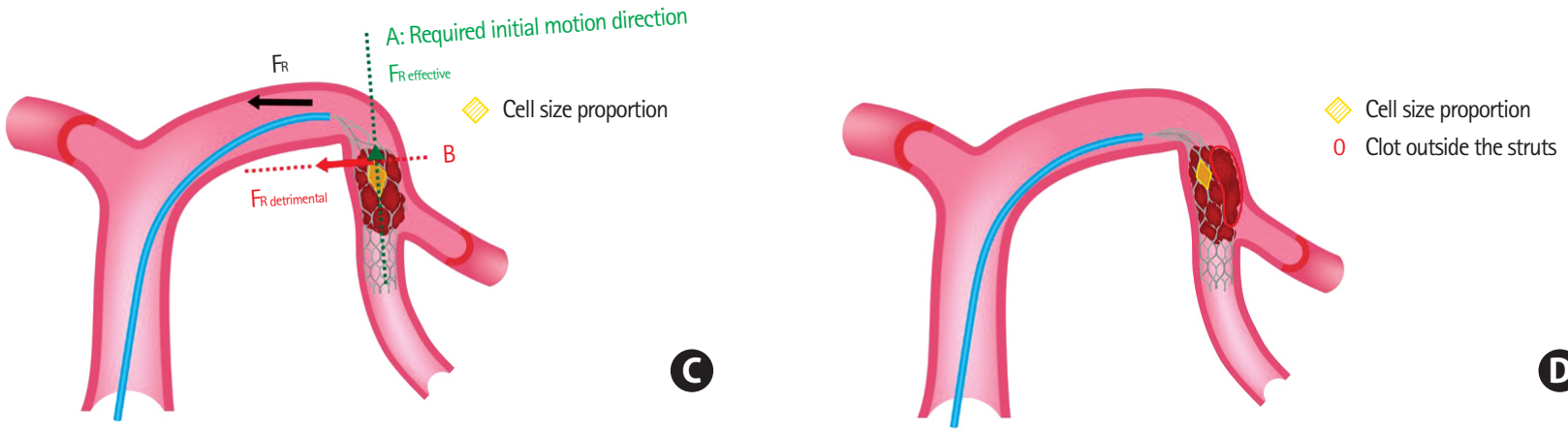

Figure 11. Tapering phenomenon during stent retrieval. (A) Stent-retriever deployed in a curved middle cerebral artery with clot within the struts of stent, note in yellow the cell size at rest. (B) Once a retrieval force $\left(F_{R}\right)$ is applied to the stent, there is decomposition of forces in the curve of the artery, $(C)$ an effective resultant force ( $F_{R}$ effective; green arrow) favoring stent retraction and a deleterious force perpendicular to this movement $\left(F_{R}\right.$ detrimental; red arrow) that $(D)$ diminishes full expansion of stent, reduces stent cell size (yellow) and forces the clot outside the stent.
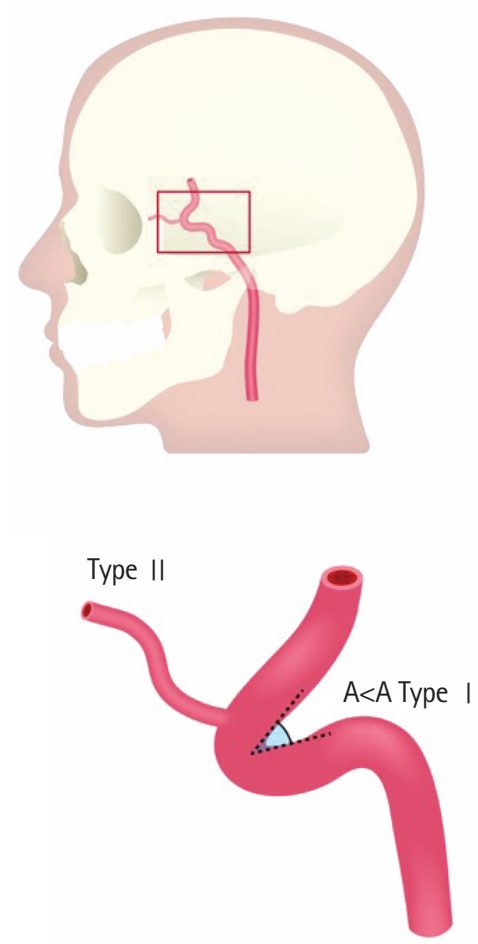

Type la
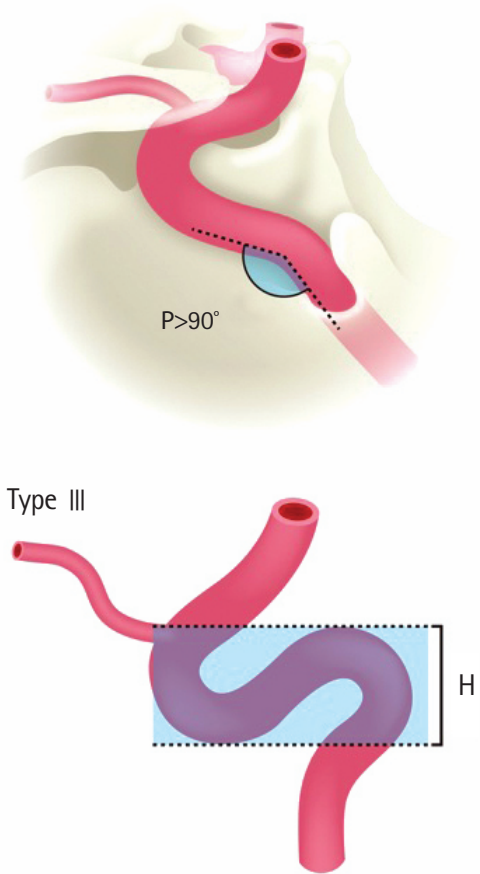

Type Ib
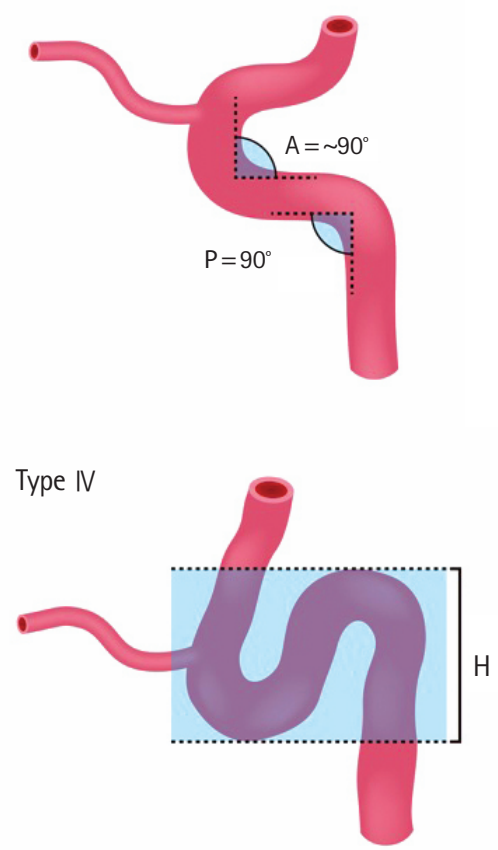

Figure 12. Degree of tortuosity of the cavernous segment of internal carotid artery (cICA). When anterior and posterior genu of cICA configurations are opened it is a type $\mathrm{I}$, that can be further divides in type la (posterior genu angle $[\mathrm{P}]$ is $\left.>90^{\circ}\right)$ and type $\mathrm{lb}\left(\mathrm{P}=90^{\circ}\right)$. Type II has a more acute angle of anterior genu (A) in comparison to type I. Type III has a superior deflection of posterior genu. Type IV is the most tortuous with a Simmons catheter shape. The higher the tortuosity (represented by the ratio $\mathrm{H} /[\mathrm{A}+\mathrm{P}]$ ), the more complex may be the procedure. $\mathrm{H}$, height between the trough of anterior genu and the peak of posterior genu. Modified from Lin et al. ${ }^{62}$ with permission from BMJ. 

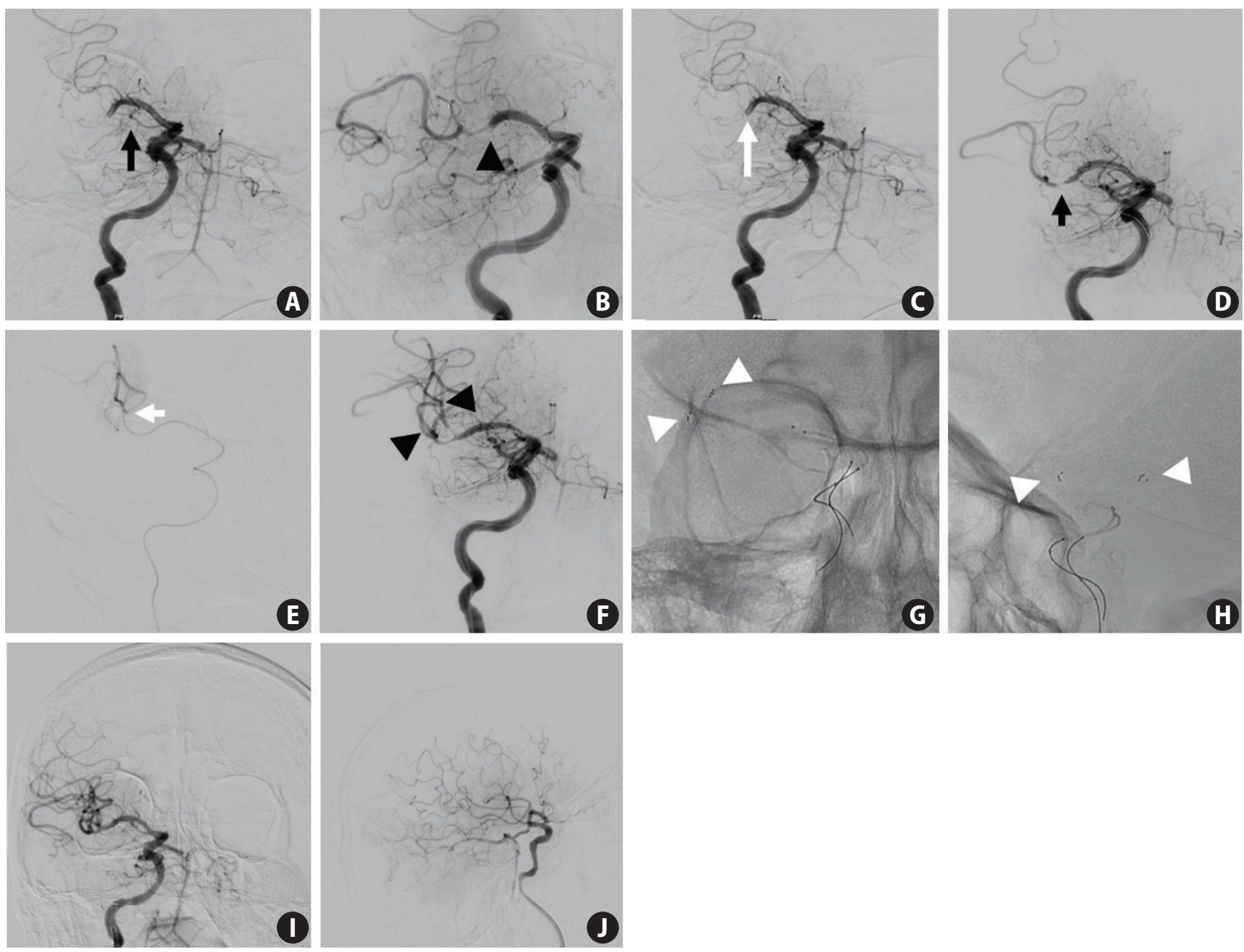

Figure 13. A 77-year-old patient with 1-hour right middle cerebral artery (MCA). (A) Right anteroposterior internal carotid angiogram depicting a distal occlusion in a curved (or diving ) M1 segment (long black arrow). (B) Anteroposterior internal carotid artery (ICA) angiographic acquisition with a Solitaire stent-retriever (Medtronic) $4 \times 40 \mathrm{~mm}$ in place delineating the curved MCA (short black arrowhead). (C) Anteroposterior angiogram of ICA after two passes with Solitaire stent-retriever $4 \times 40 \mathrm{~mm}$ showing a reperfusion failure (modified thrombolysis in cerebral infarction [mTICl] of 0) (long white arrow). (D) Solitaire stent-retriever $4 \times 40 \mathrm{~mm}$ was deployed in the inferior branch of a MCA bifurcation (short black arrow). (E) A Rebar 18 Microcatheter (Medtronic) 0.021" was navigated over a wire 0.014 " in the antero-superior branch (short white arrow) then (F) a second Solitaire stent-retriever $4 \times 40 \mathrm{~mm}$ was deployed in Y-configuration (black arrowheads). (G) Unsubstracted anteroposterior and $(\mathrm{H})$ lateral view showing Solitaire stent-retriever $4 \times 40 \mathrm{~mm}$ deployed in the inferior and superior branch of a MCA (white arrowheads). After one pass of Y-configuration stent-retrievers full reperfusion (mTICl of 3) was obtained as shown in (I) anteroposterior (J) and lateral acquisition of ICA.

force required to dislodge the clot ( $F_{R}$ effective). Although the operator may use an optimal technique during retrieval, the clot may not be displaced or may be pushed to the other branch. In these situations, we suggest the use of the double-stent technique ( $Y$ configuration) as a rescue treatment to increase clotdevice interaction and reduce the friction force of the clot with the vessel wall (Figure 13).67,68 Given the higher associated costs and potentially higher risks, we tend to reserve this technique only after the failure of CA alone or in combined techniques with SR.

\section{Conclusions}

Endovascular reperfusion provides overwhelming benefits in both early and late time windows. Nonetheless, failure to achieve effective reperfusion occurred in up to $25 \%$ of cases in recent trials. The reasons for a lack of treatment response are multifactorial and manifest differently, including a higher number of passes, longer PTs, and failed or incomplete reperfusion. While endovascular treatment technology is rapidly evolving, it remains critical to better understand the specific mechanisms underlying the individual challenges faced in daily practice as this should guide our choices of devices and tech- 
niques. Unfavorable anatomical factors are a major obstacle during endovascular AIS treatment. Prompt identification of associated features might enable appropriate strategies to overcome vascular anatomy challenges, saving time and ensuring better angiographic and clinical outcomes.

\section{Disclosure}

Raul Gomes Nogueira reports consulting fees for advisory roles with Stryker Neurovascular, Cerenovus, Medtronic, Phenox, Anaconda, Genentech, Biogen, Prolong Pharmaceuticals, Imperative Care and stock options for advisory roles with Brainomix, Viz-Al, Corindus Vascular Robotics, Vesalio, Ceretrieve, Astrocyte and Cerebrotech. Other authors have no financial conflicts of interest.

\section{Acknowledgments}

We thank Hyunmin Lee (Department of Neurology, Ajou University Hospital, Ajou University School of Medicine, Suwon, Korea) for preparing the illustrations in this paper.

\section{References}

1. Albers GW, Marks MP, Kemp S, Christensen S, Tsai JP, OrtegaGutierrez S, et al. Thrombectomy for stroke at 6 to 16 hours with selection by perfusion imaging. N Engl J Med 2018;378: 708-718.

2. Berkhemer $O A$, Fransen $P S$, Beumer $D$, van den Berg $L A$, Lingsma $H F$, Yoo $A J$, et al. A randomized trial of intraarterial treatment for acute ischemic stroke. N Engl J Med 2015;372: 11-20.

3. Bracard S, Ducrocq $X_{1}$ Mas JL, Soudant M, Oppenheim C, Moulin $T$, et al. Mechanical thrombectomy after intravenous alteplase versus alteplase alone after stroke (THRACE): a randomised controlled trial. Lancet Neurol 2016;15:1138-1147.

4. Campbell BC, Mitchell PJ, Kleinig TJ, Dewey HM, Churilov L, Yassi $\mathrm{N}$, et al. Endovascular therapy for ischemic stroke with perfusion-imaging selection. N Engl J Med 2015;372:10091018.

5. Goyal M, Demchuk AM, Menon BK, Eesa M, Rempel JL, Thornton J, et al. Randomized assessment of rapid endovascular treatment of ischemic stroke. N Engl J Med 2015; 372:1019-1030.

6. Jovin TG, Chamorro A, Cobo E, de Miquel MA, Molina CA,

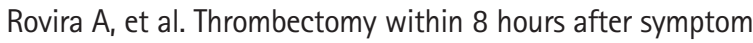
onset in ischemic stroke. N Engl J Med 2015;372:2296-2306.

7. Nogueira RG, Jadhav AP, Haussen DC, Bonafe A, Budzik RF,
Bhuva $\mathrm{P}$, et al. Thrombectomy 6 to 24 hours after stroke with a mismatch between deficit and infarct. $N$ Engl J Med 2018;378:11-21.

8. Saver JL, Goyal M, Bonafe A, Diener HC, Levy El, Pereira VM, et al. Stent-retriever thrombectomy after intravenous t-PA vs. t-PA alone in stroke. N Engl J Med 2015;372:2285-2295.

9. Martins S, Mont'Alverne F, Pontes-Neto O, Rebello LC, Silva GS, Lima F, et al. Randomization of endovascular treatment with stent-retriever and/or thromboaspiration vs. best medical therapy in acute ischemic stroke due to large vessel occlusion trial (RESILIENT): final results. Eur Stroke J 2019;4(1 Suppl):781.

10. Zaidat 00, Castonguay AC, Linfante I, Gupta R, Martin CO, Holloway WE, et al. First pass effect: a new measure for stroke thrombectomy devices. Stroke 2018;49:660-666.

11. Baek JH, Kim BM, Heo JH, Nam HS, Kim YD, Park H, et al. Number of stent retriever passes associated with futile recanalization in acute stroke. Stroke 2018;49:2088-2095.

12. Bourcier R, Saleme $S$, Labreuche J, Mazighi M, Fahed R, Blanc $R$, et al. More than three passes of stent retriever is an independent predictor of parenchymal hematoma in acute ischemic stroke. J Neurointerv Surg 2019;11:625-629.

13. Huang $X$, Cai $Q$, Xiao L, Gu M, Liu Y, Zhou Z, et al. Influence of procedure time on outcome and hemorrhagic transformation in stroke patients undergoing thrombectomy. J Neurol 2019;266:2560-2570.

14. Ribo M, Flores A, Rubiera M, Pagola J, Mendonca N, Rodriguez-Luna $D$, et al. Difficult catheter access to the occluded vessel during endovascular treatment of acute ischemic stroke is associated with worse clinical outcome. J Neurointerv Surg 2013;5 Suppl 1:i70-i73.

15. Saver JL, Goyal M, van der Lugt A, Menon BK, Majoie CB, Dippel DW, et al. Time to treatment with endovascular thrombectomy and outcomes from ischemic stroke: a metaanalysis. JAMA 2016;316:1279-1288.

16. Ribo M, Molina CA, Cobo $E$, Cerdà N, Tomasello A, Quesada $\mathrm{H}$, et al. Association between time to reperfusion and outcome is primarily driven by the time from imaging to reperfusion. Stroke 2016;47:999-1004.

17. Alawieh A, Vargas J, Fargen KM, Langley EF, Starke RM, De Leacy $R$, et al. Impact of procedure time on outcomes of thrombectomy for stroke. J Am Coll Cardiol 2019;73:879890.

18. Hassan $A E$, Shariff $U$, Saver $J$, Goyal $M$, Liebeskind $D$, Jahan $\mathrm{R}$, et al. Impact of procedural time on clinical and angiographic outcomes in patients with acute ischemic stroke receiving endovascular treatment. J Neurointerv Surg 2019;1 1:984-988. 
19. Mazighi $M$, Chaudhry SA, Ribo $M$, Khatri $P$, Skoloudik $D$, Mokin $M$, et al. Impact of onset-to-reperfusion time on stroke mortality: a collaborative pooled analysis. Circulation 2013;127:1980-1985.

20. Snelling BM, Sur S, Shah SS, Chen S, Menaker SA, McCarthy DJ, et al. Unfavorable vascular anatomy is associated with increased revascularization time and worse outcome in anterior circulation thrombectomy. World Neurosurg 2018;120:e976e983.

21. Spiotta AM, Vargas J, Turner R, Chaudry MI, Battenhouse $H_{\text {, }}$ Turk AS. The golden hour of stroke intervention: effect of thrombectomy procedural time in acute ischemic stroke on outcome. J Neurointerv Surg 2014;6:511-516.

22. Bourcier R, Hassen WB, Soize $S$, Roux P, Labreuche J, Kyheng $M$, et al. Susceptibility vessel sign on MRI predicts better clinical outcome in patients with anterior circulation acute stroke treated with stent retriever as first-line strategy. $J$ Neurointerv Surg 2019;11:328-333.

23. Kaesmacher J, Gralla J, Mosimann PJ, Zibold F, Heldner MR Piechowiak $E_{1}$ et al. Reasons for reperfusion failures in stentretriever-based thrombectomy: registry analysis and proposal of a classification system. AJNR Am J Neuroradiol 2018;39: 1848-1853.

24. Lee JS, Hong JM, Kim JS. Diagnostic and therapeutic strategies for acute intracranial atherosclerosis-related occlusions. J Stroke 2017;19:143-151.

25. Jeong DE, Kim JW, Kim BM, Hwang W, Kim DJ. Impact of balloon-guiding catheter location on recanalization in patients with acute stroke treated by mechanical thrombectomy. AJNR Am J Neuroradiol 2019;40:840-844.

26. Tokunaga S, Tsurusaki Y, Sambongi Y, Tsumoto T. Balloon-inflation anchoring technique for insertion of a guiding catheter in acute mechanical thrombectomy. J Neuroendovascular Ther 2017;11:53-58.

27. Rangel-Castilla L, Shakir HJ, Siddiqui AH. Initial experience with a multiple parallel guidewire support system for complex tortuous aortic arch navigation and great vessel catheterization: technical note. Neurosurg Focus 2017;42:E14.

28. Crowley RW, Abla AA, Ducruet AF, McDougall CG, Albuquerque FC. Novel application of a balloon-anchoring technique for the realignment of a prolapsed pipeline embolization device: a technical report. J Neurointerv Surg 2014;6:439-444.

29. Snelling BM, Sur S, Shah SS, Khandelwal P, Caplan J, Haniff $\mathrm{R}$, et al. Transradial cerebral angiography: techniques and outcomes. J Neurointerv Surg 2018;10:874-881.

30. Kolkailah AA, Alreshq RS, Muhammed AM, Zahran ME, Anas El-Wegoud M, Nabhan AF. Transradial versus transfemoral approach for diagnostic coronary angiography and percuta- neous coronary intervention in people with coronary artery disease. Cochrane Database Syst Rev 2018;4:CD012318.

31. Chen SH, Snelling BM, Sur S, Shah SS, McCarthy DJ, Luther $E_{1}$ et al. Transradial versus transfemoral access for anterior circulation mechanical thrombectomy: comparison of technical and clinical outcomes. J Neurointerv Surg 2019;11:874878.

32. Zussman BM, Tonetti DA, Stone J, Brown M, Desai SM, Gross $B A$, et al. A prospective study of the transradial approach for diagnostic cerebral arteriography. J Neurointerv Surg 2019; 11:1045-1049.

33. Baek JH, Kim BM, Kang DH, Heo JH, Nam HS, Kim YD, et al. Balloon guide catheter is beneficial in endovascular treatment regardless of mechanical recanalization modality. Stroke 2019;50:1490-1496.

34. Zussman BM, Tonetti DA, Stone J, Brown M, Desai SM, Gross $B A$, et al. Maturing institutional experience with the transradial approach for diagnostic cerebral arteriography: overcoming the learning curve. J Neurointerv Surg 2019;11:12351238.

35. Haussen DC, Nogueira RG, DeSousa KG, Pafford RN, Janjua N, Ramdas KN, et al. Transradial access in acute ischemic stroke intervention. J Neurointerv Surg 2016;8:247-250.

36. Maud A, Khatri R, Chaudhry MRA, Vellipuram A, Cruz-Flores $\mathrm{S}$, Rodriguez GJ. Transradial access results in faster skin puncture to reperfusion time than transfemoral access in posterior circulation mechanical thrombectomy. J Vasc Interv Neuro/ 2019;10:53-57.

37. Snelling BM, Sur S, Shah SS, Caplan J, Khandelwal P, Yavagal $D R$, et al. Transradial approach for complex anterior and posterior circulation interventions: technical nuances and feasibility of using current devices. Oper Neurosurg (Hagerstown) 2019;17:293-302.

38. Sur S, Snelling B, Khandelwal P, Caplan JM, Peterson EC, Starke RM, et al. Transradial approach for mechanical thrombectomy in anterior circulation large-vessel occlusion. Neurosurg Focus 2017;42:E13.

39. Horton TG, Kalapos P, Cockroft KM. Brachial artery approach for endovascular treatment of posterior circulation intracranial vascular disease: technique and application in 5 cases. $J$ Stroke Cerebrovasc Dis 2012;21:68-74.

40. Koge J, Iwata T, Hashimoto T, Mizuta S, Nakamura Y, Tanaka $E_{1}$ et al. Carotid artery stenting with proximal embolic protection via the transbrachial approach: sheathless navigation of a 9-F balloon-guiding catheter. Neuroradiology 2018;60: 1097-1101.

41. Okawa M, Tateshima S, Liebeskind D, Ali LK, Thompson ML, Saver J, et al. Successful recanalization for acute ischemic 
stroke via the transbrachial approach. J Neurointerv Surg 2016;8:122-125.

42. Stavroulakis K, Usai MV, Torsello G, Schwindt A, Stachmann

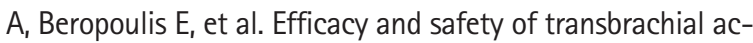
cess for iliac endovascular interventions. J Endovasc Ther 2016;23:454-460.

43. Yamaguchi S, Horie N, Morofuji Y, Satoh K, Suyama K. Rapid recanalization using TrevoProVue through a 4.2 Fr catheter without a guiding catheter via transbrachial approach: a case report. NMC Case Rep J 2017;4:97-99.

44. Blanc R, Piotin M, Mounayer C, Spelle L, Moret J. Direct cervical arterial access for intracranial endovascular treatment. Neuroradiology 2006;48:925-929.

45. Mokin M, Snyder KV, Levy El, Hopkins LN, Siddiqui AH. Direct carotid artery puncture access for endovascular treatment of acute ischemic stroke: technical aspects, advantages, and limitations. J Neurointerv Surg 2015;7:108-113.

46. Roche A, Griffin E, Looby S, Brennan P, O'Hare A, Thornton J, et al. Direct carotid puncture for endovascular thrombectomy in acute ischemic stroke. J Neurointerv Surg 2019;11: 647-652.

47. Cuellar H, Guimaraens L, Ambekar S, Vivas E, Theron J. Angioseal as a hemostatic device for direct carotid puncture during endovascular procedures. Interv Neuroradiol 2015;21: 273-276.

48. Wiesmann M, Kalder J, Reich A, Brockmann MA, Othman A, Greiner $A$, et al. Feasibility of combined surgical and endovascular carotid access for interventional treatment of ischemic stroke. J Neurointerv Surg 2016;8:571-575.

49. Nagata $T$, Masumoto $K$, Hayashi $Y$, Watanabe $Y$, Kato $Y$, Katou F. Three-dimensional computed tomographic analysis of variations of the carotid artery. J Craniomaxillofac Surg 2016:44:734-742.

50. La Barbera G, La Marca G, Martino A, Lo Verde R, Valentino F, Lipari $D$, et al. Kinking, coiling, and tortuosity of extracranial internal carotid artery: is it the effect of a metaplasia? Surg Radiol Anat 2006:28:573-580.

51. Jankowitz BT, Shayan M, Robertson AM, Chun Y. In vitro assessment of the trackability of neurovascular intermediate catheters: a comparative analysis. J Med Eng Technol 2014; 38:379-384.

52. Lee S, Gong TS, Lee YW, Kim HJ, Kweon CY. The benefits of Navien intracranial support catheter for endovascular treatment. J Cerebrovasc Endovasc Neurosurg 2016;18:234-238.

53. Turk A, Manzoor MU, Nyberg EM, Turner RD, Chaudry I. Initial experience with distal guide catheter placement in the treatment of cerebrovascular disease: clinical safety and efficacy. J Neurointerv Surg 2013;5:247-252.
54. Lapergue B, Labreuche J, Piotin M; On behalf of the ASTER2 Trial Investigators. Combined use of contact aspiration and the stent retriever technique versus stent retriever alone for recanalization in acute cerebral infarction: the randomized ASTER2 trial. Eur Stroke J 2019;4(1 Suppl):5.

55. Schwaiger BJ, Gersing AS, Zimmer C, Prothmann S. The curved MCA: influence of vessel anatomy on recanalization results of mechanical thrombectomy after acute ischemic stroke. AJNR Am J Neuroradiol 2015;36:971-976.

56. Yamamoto $S$, Yamagami $H$, Todo $K$, Kuramoto $Y$, Ishikawa $T$,

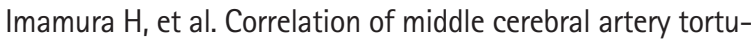
osity with successful recanalization using the Merci retrieval system with or without adjunctive treatments. Neurol Med Chir (Tokyo) 2014;54:113-119.

57. Zhu L, Liebeskind DS, Jahan R, Starkman S, Salamon N, Duckwiler $\mathrm{G}$, et al. Thrombus branching and vessel curvature are important determinants of middle cerebral artery trunk recanalization with Merci thrombectomy devices. Stroke 2012;43:787-792.

58. Bernava G, Rosi A, Boto J, Brina O, Kulcsar Z, Czarnetzki C, et al. Direct thromboaspiration efficacy for mechanical thrombectomy is related to the angle of interaction between the aspiration catheter and the clot. J Neurointerv Surg 2020; 2:396-400.

59. Cai $Y$, Spelle L, Wang H, Piotin M, Mounayer C, Vanzin JR, et al. Endovascular treatment of intracranial aneurysms in the elderly: single-center experience in 63 consecutive patients. Neurosurgery 2005;57:1096-1102.

60. Sanders-Taylor C, Kurbanov A, Cebula H, Leach JL, Zuccarello M, Keller JT. The carotid siphon: a historic radiographic sign, not an anatomic classification. World Neurosurg 2014;82: 423-427.

61. Krayenbuehl H, Yasargil M. Cerebral Angiography. 2nd ed. New York, NY: Thieme Medical Publishers, 1982:53.

62. Lin LM, Colby GP, Jiang B, Uwandu C, Huang J, Tamargo RJ, et al. Classification of cavernous internal carotid artery tortuosity: a predictor of procedural complexity in Pipeline embolization. J Neurointerv Surg 2015;7:628-633.

63. Jiang WJ, Wang YJ, Du B, Wang SX, Wang GH, Jin M, et al. Stenting of symptomatic M1 stenosis of middle cerebral artery: an initial experience of 40 patients. Stroke 2004;35: 1375-1380.

64. Takahira K, Kataoka T, Ogino T, Endo H, Nakamura H. Efficacy of a coaxial system with a compliant balloon catheter for navigation of the Penumbra reperfusion catheter in tortuous arteries: technique and case experience. J Neurosurg 2017; 126:1334-1338.

65. Peeling $L$, Fiorella D. Balloon-assisted guide catheter position- 
ing to overcome extreme cervical carotid tortuosity: technique and case experience. J Neurointerv Surg 2014;6:129133.

66. Haussen DC, Al-Bayati AR, Eby $B$, Ravindran $K$, Rodrigues $\mathrm{GM}$, Frankel MR, et al. Blind exchange with mini-pinning technique for distal occlusion thrombectomy. J Neurointerv Surg 2020;12:392-395.
67. Aydin K, Barburoglu M, Oztop Cakmak O, Yesilot N, Vanli ENY, Akpek S. Crossing Y-solitaire thrombectomy as a rescue treatment for refractory acute occlusions of the middle cerebral artery. J Neurointerv Surg 2019;11:246-250.

68. Patro SN, lancu D. Dual-stent retrieval for mechanical thrombectomy of refractory clot in acute stroke as a rescue technique. CMAJ 2017;189:E634-E637. 